\title{
The Relationship of Online Discourse on the Values of Bitcoin and Ethereum
}

Advanced Topics in Social Network Analysis

By

\section{Gil Benchlouch}




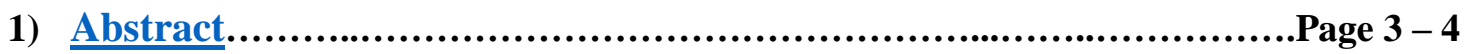

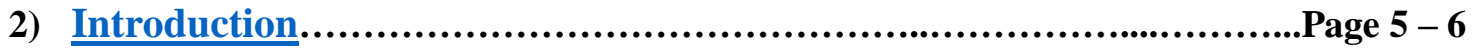

3) Literature Review.........................................................Page 7 - 22

3.1) What is Currency......................................................Page 7 - 8

3.1.1) Traditional Forms of Investment and Evolution............................Page 8 - 10

3.1.2) What are Cryptocurrencies?..............................................Page 10 - 11

3.1.3) Process of production \& Limitations of Creation..........................Page 11 - 12

3.1.4) Control and Management of Cryptocurrencies...........................Page 12 - 14

3.1.5) Different Types of Cryptocurrencies..........................................Page 14

3.1.6) Proof of Stake....................................................................Page 14

3.1.7) Valuation and Influencers of Value......................................Page 15 - 16

3.1.8) Theories and Models of Communications.....................................Page 16 - 20

3.1.9) Literature Review.............................................................Page 20 - 22

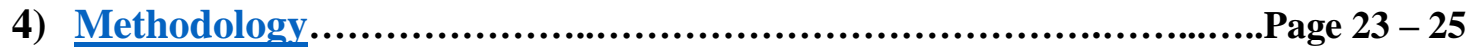

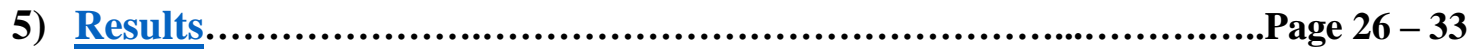

6) Discussion....................................................................Page 34 - 38

7) Conclusion.................................................................Page 39 - 40 
The Relationship of Online Discourse on the Values of Bitcoin and Ethereum

\section{Abstract}

With technology brazenly breaching through society's barriers in countless diverse fields, the 21 st century has revolutionized many age-old industries. One of the largest areas within society influenced by the progress of technology are the fields of finances, economy, and investment, coupled with the aspect of social influence. With this shift in society parallel to the advancement of contemporary technologies, thus becoming increasingly reliant on the tools made available, the complex yet traditional world of finance has pivoted, becoming contingent upon the use of cutting-edge technologies. This critical shift has introduced the world of Fintech, providing many innovative fiscal opportunities. The coined term, Fintech, is a general term referring to products as services for fiscal activities developed by entities unrelated to banks, insurance firms, nor online companies, providing alternatives to the traditional options available to the general public. (Gulamhuseinwala, Bull and Lewis, 2015). Resultantly of this Fintech trend, one of the largest and most promising fields of contemporary investment is recognized as that of Cryptocurrencies, with Bitcoin and Ethereum being the most recognized and heavily traded currencies.

Many positive traits can be used to define the novelty of this new economy, with one of the main aspects being its peer to peer (P2P) nature of its trading process. However, beyond the tremendous advancements visible within the process of Cryptocurrency production and trade, one of the most important aspects is the influencers upon the valuation of the different currencies. Similarly to the progression of the economy which has transported the financial world to a digital economy, so has the social world, advancing discourse regarding many topics to the online environment. Thus, it is critical to analyze and assess the nature of online discourse regarding Cryptocurrencies. Explicitly, the chatter preceding to sharp rises and falls with Bitcoin and Ethereum, the most recognizable coins. Additionally, it is imperative to appraise the trends in the behavior and quantity of online discourse prior to a significant drop in Ethereum \& Bitcoin.

Within the online arena, there are countless different outlets and platforms for people to express themselves in general, or more importantly in this instance regarding the topic of Cryptocurrencies. By using platforms that are designated for discussion regarding financial topics or general social media platforms, the public is provided a critical platform utilized by countless individuals, many of whom are increasingly involved with the aforementioned topics. These platforms stipulate a stage for these individuals, who have 
The Relationship of Online Discourse on the Values of Bitcoin and Ethereum

become critical by voicing their opinions, thoughts, and experiences. Many of these influencers are sought after for their knowledge, specifically influencing the behavior of others. However, it is critical to evaluate the importance of additional aspects beyond the superficial such as who are the influencers, rather elements such as the content or nature of what is being discussed. Resultantly to trends of content, nature, and volume of what is being discussed in the online arena., people's behavior regarding investments, specifically within Cryptocurrencies, are very possibly subjected to the influence of others, leading to rises and falls in coin valuation. 
The Relationship of Online Discourse on the Values of Bitcoin and Ethereum

\section{Introduction}

Traditionally, equity has been a major determinant regarding social status and position in society, however, contemporarily the relationship between equity and social aspects prove to be more reciprocal than ever before. Another intrinsic field of study throughout the past century has been the field of social influence. As such, sociologists have attempted to decipher the different elements and factors that lead to the influence of one party upon another. This impact may occur on an individual level, or more interestingly, on a much larger scale. The complexity of this phenomenon is extremely extensive, especially considering the infinite factors that may impact the opinions and behaviors of others such as conformity, social status and structure, along with countless others (Turner, 1993). Consequently, with the development of time and technology, the media has posed a significant area of interest regarding the study of social influence, as it has always provided a stepping stone for the dispersion of knowledge, ideas, opinions. Paired with the advancement of technologies, the media has been progressively equipped with the ability to grasp increasingly distant and larger audiences with messages of varied content, resultantly stipulating the ability to influence and stimulate said audiences as a result (Nisbet \& Kotcher, 2009). This paper aims to provide evidence linking the relationship between social media activity, specifically online chatter, and the subsequent effects upon the value of Cryptocurrencies, one of the most interesting and controversial domains in present-day economy and society.

As technology has evolved over the past several centuries from physical transactions of equity, often between individuals from the general public and employees of large financial institutions such as banks, technology has now revolutionized the transfer and concept of equity trade. Immediately following significant drops in the traditional global economy, the need for a new economy based upon intangible currencies with decentralized wealth placed directly in the hands of the public was met with the foundation of Cryptocurrencies. This innovative economy was developed using the foundations of cutting-edge technologies in order to provide a seamless and streamlined form of trade, secure by critical methodologies in order to support its existence of an unregulated economy controlled by the fiscal activities by the general public trading within.

"Virtual currencies, perhaps most notably Bitcoin (BTC), have captured the imagination of some, struck fear among others, and confused the heck out of the rest of us." United States Senator Thomas Carper, managed to captivate some of the major 
concerns surrounding Cryptocurrencies voiced by the public in recent years (Rosic, 2017). This powerful statement was made at one of the most critical points in time, not only in the domain of technological development, but also for the realm of social media. Throughout time, technology and communications have proven to be determining factors upon the most defining aspects of society. One of the fields most influenced by contemporary technologies, is that of equity investments and finances. Resultantly, many assets have shifted from the form of the investment, their methodology of trade, and finally the interactivity of the public and investors regarding the industry. Thus, one of the most notable trends in the realm of finances and investments throughout the $21^{\text {st }}$ century has been the evolution and prevalence of Cryptocurrencies. This paper aims to clarify the base upon which Cryptocurrencies have come to exist, to clarify what they are, the process of their creation, and most importantly, the potential influence that social media activity of the general public has upon their value. 
The Relationship of Online Discourse on the Values of Bitcoin and Ethereum

\section{Literature Reviews}

\subsection{What is Currency?}

While assessing the essence of Cryptocurrency, one must be able to answer the basic question, what is currency? When examining the longevity of finance over time, it is notable that currency has existed throughout all periods of recorded history, developing over time and evolving according to the technology present. Thus, currency has always been the representation of value or wealth, and as such, during some periods of time, the object of value itself has often been the actual form of currency. As time has progressed, currency has evolved from its tangible and physical form to a non-tangible, virtual entity. In its non-tangible form, currency has become the representation of the specific object or quantity of value being traded between the "giver" and "receiver" of goods (FXCM, 2015).

Historically, the earliest forms of currency can be traced throughout history until approximately 10,000 B.C., with economies based upon the barter system of goods. These goods have ranged from hunting tools, livestock, clothing, weaponry, and other items of value. By approximately 8,000 B.C., currency had evolved from the specific object of value being traded, to objects symbolizing value or wealth. The Mesopotamians were the first recognized civilization to manage an economy based on such objects, trading for different objects determined to represent their adequate value. Eventually, this evolved into economies of coin and paper currencies, eventually becoming the officially recognized and traditional forms of currencies upon which, all current economies have based upon for the past 9,000 years (FXCM, 2015). One of the major turning points in history regarding the progression of currency transpired in 1252, in Florence, the contemporary hub of trade in the Old World, with the commencement of minting of the Florin as the local and regional currency. The introduction of the Florin was revolutionary to the European economy, as the coin currency reintroduced gold as the casting material for coin currency for the first time since the $7^{\text {th }}$ century, replacing silver. This had tremendous importance, as the coin itself had symbolic value and materialistic value for its content (Shaw, 1896).

Critically, the symbolic and material forms of currency have always maintained the common purpose of representation of value, either as an abstraction or direct demonstration. As such, with the advancement of technology and the norms presented by society's presence in the virtual age, currency has subsequently mutated. Consequently, the development has ranged from the entities of stocks, bonds, real-estate, and shifted to the introduction of virtual currencies. Therefore, the global economy has been revolutionized 
The Relationship of Online Discourse on the Values of Bitcoin and Ethereum

by the concept of currency and value, resulting from taking an entity that has no tangible existence whatsoever, yet possessing a collective worth in the hundreds of billions for many of the separate Cryptocurrencies.

\subsubsection{Traditional Forms of Investment and Evolution}

Historically, the development of fiscal activities has advanced tremendously, far beyond the traditional barter system and sales of goods, into diverse national and global monetary systems, both tangible and virtual. Over time, societies shifted from the simple trade of goods or currency and began to invest their finances in different markets to supplement financial income. The different fields of economic interest became rich with economic opportunities across the myriad of different industries that had become popular for investment. Over the past centuries, it became a norm for people to invest their earnings and savings into alternative fields of fiscal interest, some of which are tangible such as real-estate, while others are more abstract and non-tangible such as stocks, bonds, and Cryptocurrencies (Investopedia, 2018).

One of the main industries for financial investments over the past centuries, has been the industry of stocks. Stocks are an age-old form of investment representing a stake in a company, by vesting equity in exchange for stakes in the company. These stakes have fiscal value which is determined within the exchange that they are traded, with the fluctuations of their values leading to loss or gain for the investor. Additionally, an adequate number of shares, which are the units of stock, can result in voting power and control over a company. Dating back to as far back as the $14^{\text {th }}$ century, the traders of Venice, which served as the European hub for merchants at the time, traded in securities as vestments with governments and monarchies, very similar to modern day stock markets. The earliest official form of the modern-day stock exchange dates back to the $16^{\text {th }}$ century in Belgium, with brokers managing debts and investments in one centralized location, maintaining the books detailing these transactions. In 1792, the New York Stock Exchange (NYSE) was established, ultimately evolving into the most powerful and fiscally vested stock exchange globally. Eventually, the evolution of the stock exchange replaced governments with companies, whose actions and corporate governance influence the value of the company's stock. In most instances, when companies perform major business activities, release new major products to their lines, perform significant alterations in their corporate governance, the stock prices change according to the response by the public trading these shares. Therefore, a feedback loop forms accordingly where the public's 
response can significantly raise or drop the value of the company's stock price. Currently, a significant amount of the discourse regarding company activities occur on social media platforms, and these posts finally result in these fluctuations in stock price (Beattie, 2018).

In 1987, a devastating crash of the global stock markets, known as "Black Monday" led to dramatic losses globally of vested equity in stock exchanges. Resultantly, in the immediate aftermath investors began to shift from investing in stocks to what was considered to be a more stable stake, the real-estate industry (Shiller, 1987). It is critical to understand the investment patterns seen in the stock market as they are very similar and indicative of the influence upon others seen in Cryptocurrency investment.

Whereas stocks have been traded as an intangible form of value over an extensive period of time in history, another aged field of investment rather in the tangible field has been that of real estate. Historically, owning property has been one of the most consistent and arguably reliable form of investments with a steady and recurring consistent rise in value over time. As such, many researchers have sought to study and evaluate the stability of this field of investment in regard to reliability and movement throughout time and different influences on property value. Traditional investments such as real-estate are subject to shift in value by a myriad of extrinsic variables such as neighborhood, area development, and the market itself. As such, investors manage their investments in an effort to increase values of their properties, by attempting to manage the fluctuation in the market similarly to what is seen in the market activity affecting the economy of Cryptocurrency (Han \& Liang, 1995).

Despite the seeming stability of the real-estate industry to its investors and the world, drastic shifts in the market arguably set the basis for the considerations leading to the investments in Cryptocurrencies in the years soon to follow. When examining "nontraditional" forms of investments, specifically those whose values are subject to influence by social behavior, such as Cryptocurrency, one must assess historical events upon similar markets. Similarly, to Cryptocurrency, whose value is unequivocally subject to social behavior, the real-estate market has also been influenced by such behavior to an extent. Resulting from the fact that both fields operate according to a "social collateral", where the eclectic actions and behavior of all consumers in that market influence one another and the market itself in its entirety. As such, one critical case study is the widescale collapse of the real-estate industry in the United States in 2008. The events leading to this crash resulted from irresponsible and sporadic fiscal behavior whereby investors were continuously purchasing and overdrawing the government owned Fannie Mae. This government 
sponsored enterprise is responsible for managing the nation's mortgage economy, and as such became overdrawn in 2008 . This was exacerbated by the inability to recover resulting from many citizens' incapacity to repay their debt, leading to a widespread crash of the market and property values to plummet. This is an exemplary case of an economy whose fluctuations rested upon the shoulders of its investors, leading to extreme shifts, and resultantly a tremendous crash (Bandyk \& Schwartz, 2009). Thus, currency has always been an inherent and recurring aspect of investments, by investing currency either virtual or tangible in other entities, ideally increasing their value and thus the investor's income. With time, an economy has developed upon which the actual currencies such as the tangible ones of different nationalities or the virtual ones such as Cryptocurrencies are being invested in. Due to the real-estate crash in 2008 , links have been traced to the formation of Cryptocurrencies and rise in their investments, as the most well-known currency was coined in the following year, the Bitcoin (Lee, 2014).

In relation to the progression of technology at the point of the 2008 Real Estate Crash, it can be argued according to the communications theory of Technological Determinism, that the available technology of the internet facilitated in implementing the prevalence of Cryptocurrencies that we see in today's economy. This theory proposes that the major contemporary technology is in the epicenter of the process of media effects, and that the medium or technology used to deliver media is the key component of the relationship with the consumer, not the message nor content. Thus, according to Marshall McLuhan's theory, there has been a progression of technology throughout history beginning from the "Tribal Age" and ranging through the "Electronic Age". More so, it can be claimed according to the studies of Harold Innis from the Toronto School, that the foundations of the success and resilience of Cryptocurrencies rely on the fact that the technology is neither time nor space bound. This is a critical aspect from investors' point of view, as digital currencies have no "expiration date", and can be traded from any location with internet access (Marx \& Smith, 1994). Thus, in the context of the economy, it is arguable that there has been such a progression and developments within the different ages of the economy, bringing society to the prevalence of "digital economies" with the assertion of Cryptocurrencies.

\subsubsection{What are Cryptocurrencies?}

Due to the predominance of investment of Cryptocurrencies and their astronomical values, it is imperative to fully comprehend what they are and how they are formed. 
Cryptocurrency is a broad term for the myriad of different virtual currencies, created as a product of algorithms and computer programs and are secured using Cryptography. Identical to the ideology of physical form of currency in that it symbolizes the worth of something in specific quantity (Tillier, 2018). Progression in technology and the norms within the global economy have introduced new norms, digital wallets, and electronic banking. With these technologies employed in banking and currencies, the cost of handling electronic finances has lowered considerably. Prior, the customary use of digital transactions was conducted between two entities who had a significant geographic distance between them. Today, the inherent use of smartphones and ubiquitous web-connected devices, has made digital transactions and norm, competing with the prevalence of traditional currency transactions. In continuance to the rising trend of digital fiscal transactions, a noticeable minority has taken to the relatively novel form of currency, Cryptocurrencies. Cryptocurrency in its very essence is a substitute for tangible currency that is issued by governments. At its very core, one of the most important aspects of Cryptocurrencies is providing and maintaining the highest levels of security for financial transactions, part of which prevents Cryptocurrency owners from attempting to conduct the same transaction multiple times, maintaining a certain amount of control, even if decentralized over the digital currencies. Due to their very clandestine nature and the fact that these Cryptocurrencies are not regulated by any one specific government, their owners or traders can maintain a somewhat anonymous identity in their trade. As such, unlike physical currencies that are subject to national and international law, it is much easier to transport Cryptocurrencies between different countries (Luther, 2015).

\subsubsection{Process of production \& Limitations of Creation}

Unlike "official” forms of currencies, Cryptocurrencies are neither minted nor produced by the government, differently, they are the product of mathematical algorithms and computer programs specifically designed to "mine" or produce them (Tillier, 2018). The processes by which Cryptocurrency is created or "mined", are defined by developers who write these practices, basing them upon high level mathematics and computer engineering codes. The intricate extent of these codes makes these currencies nearly impenetrable, thus making duplication or counterfeit Cryptocurrency practically impossible (Martucci, 2018). The process entails the "miners" of the currencies to solve a "proof of work" algorithm, which is ultimately an intricate mathematical complexity which serves the purpose of ensuring that specific criteria are met in order for the miner to be able 
to produce more coin. If the miner is able to successfully solve this algorithmic challenge, they are then rewarded with a "block", representing a specific amount of the currency in question which is predetermined by the system in order to maintain existing coin value but allow production of additional currency (Draupnir, 2016).

Similar to natural resources, many of which are currently serving as major industries of investment such as crude oil, certain Cryptocurrencies are limited by available quantity of production. Bitcoin, the most famous Cryptocurrency was released in 2008 for trade by the public by Satoshi Nakamoto, with a pre-determined production quantity of twenty-one million units. On January $13^{\text {th }}$ of 2018 , it was reported that $80 \%$ of the entire market's Bitcoin supply had been mined and are being traded. This means that 16.8 million units of Bitcoin have been extracted by miners, leaving approximately 4.2 million viable for mining by anyone with the proper technological means to do so. This opposes the methodology of possessing pre-mined Bitcoins, which can only be done through trade. However, it is important to note that not all Cryptocurrencies are mineable by the general public, some currencies are produced in their entirety by their creators such as Ripple, IOTA, Waves, and many others (Zuckerman, 2018).

\subsubsection{Control and Management of Cryptocurrencies}

One of the most important aspects of all economies, specifically that of Cryptocurrencies, is the question regarding who controls the industry's economy, and how its economy is managed. The control resides within the activity of those who trade this type of currency, and extremely elaborate codes that are written into the currency. Furthermore, the miners of these currencies who are entrusted with noting trades, actively produce new units of Cryptocurrencies, and the fees of additional users which are paid for their transactions are imperative in the steadiness of Cryptocurrencies (Martucci, 2018). Such an economy based upon the optimistic appeal of an economy consisting of currency that is unregulated by governments and as such is not subjected for the most part by domestic laws and taxation. However, a global concern regarding Cryptocurrencies, is the manipulation of this economy to serve illicit and illegal activities and entities. As a result, the nation's Deputy Finance Minister of the time, Alexey Moiseev, asserted that the nation would move to ban Bitcoin in an effort to combat the adverse effects on the national currency and local economy. In consequence of the Russian government's attempts to paralyze the nation's Crypto-community, many websites have been disabled by the Russian authorities. However, local courts such as that of St. Petersburg, are overturning 
rulings by the government limiting citizens trading Cryptocurrencies and restoring the websites that enable this trade (Tassev, 2018).

The issue of regulation is another major aspect of this economy that has troubled many people, due to its anonymous, "open", and unfettered nature. Nevertheless, there is a strong concern regarding the possibility of manipulation of Cryptocurrencies for negative intentions. Unregulated by any official government entity or organization, another aspect critical for the understanding of Cryptocurrencies, are how they are managed. Despite, the libertarian nature of Cryptocurrencies, many western nations have attempted to place limitations and national regulations through legislation. Russia had attributed steep and consistent falls in value to its currency, the Ruble, greatly to the illicit activities that the clandestine nature of Bitcoin that this unique economy allows.

Consequently, Blockchain Technology is the digital form of transaction by which these transactions take place between owners of the different currencies. The term "Blockchain" refers to the technology used to manage Cryptocurrencies, similarly to a digital ledger, whereby transactions are recorded publicly. According to Don and Alex Tapscott, authors of The Blockchain Revolution, "The Blockchain is an incorruptible digital ledger of economic transactions that can be programmed to record not just financial transactions but virtually everything of value." The data that is compiled throughout the Blockchain technology is a source of data that is widely shared in a public fashion throughout the net. As such each transaction yields influence on the value of the specific Cryptocurrency that is traded. The data collected through Blockchain does not exist on any one single computer or device, rather a large collection of different devices, making the virtual ledger nearly impossible to penetrate. In order to ensure its decentralized existence and maintain its security, Blockchain in its very essence can neither be controlled by any one single body nor can it be forced to collapse through any one single point of origin (Knowledge@Wharton, 2017).

One of the largest appeals that Cryptocurrencies possess towards those who trade and own them is the quasi-anonymity that they allow. Due to the lack of governmental regulation, a major issue surrounding the current trend of Cryptocurrencies is the association with terrorism and organized crime. With no officially recognized entity supervising and regulating the trade and transport of Cryptocurrencies, this virtual economy is not subjected to specific demands and regulations as are traditional currencies when crossing state or international borders. The expansions and developments stemming from Financial Technology (FinTech) and its novelties yields a multitude of opportunities 
and possibilities for its users. Some of which are electronic payments and transfers, cellular transaction services, and many others. As such the ubiquitous nature that FinTech allows, provides a cross border transferability that endorses illegal activities ranging from terror to organized crime. Another major concern regarding Cryptocurrencies is money laundering, by trading "dirty money" resulting from illegal activity in exchange for virtual currencies of equal value, which then can be traded in exchange for clean money. One of the critical aspects of this process, is determining the value of these currencies (Salami, 2017).

\subsubsection{Different Types of Cryptocurrencies}

Just as the traditional economy, Cryptocurrency refers to an extensive range of different types of currencies. Subsequent to its creation in 2008, Bitcoin has earned the reputation as the most well-known Cryptocurrency global. Due to the extent of its familiarity, despite their astronomical values respectively, all coins other than Bitcoin are commonly referred to as "Altcoins" (Farrel, 2015). According to the online database CoinMarketCap, at the time this paper was written there were 1,614 different active Cryptocurrencies available for trading (CoinMarketCap, 2018). The vast number of coins indicate the success and importance that the paradigm of Cryptocurrency has accumulated since the foundation of the Bitcoin in 2008. Today, the general public has a plurality of possibilities and opportunity regarding investments in the field in question.

\subsubsection{Proof of Stake}

Due to the intangible nature that defines the different Cryptocurrencies, investors require validation substantiating their investments, this is known as Proof of Stake. The concept of Proof of Stake provides investors with digital files substantiating their investments, essentially giving them something proving ownership of their Cryptocurrency. These files are often secure using advanced cyber-security technologies, in order to protect these investments using encryption and other methodologies. Thus, the vast equity accumulated by the masses in the different Cryptocurrencies are digitally observed similarly in fashion to the way that banks secure traditional equity. Therefore, this liquid digital equity is critical to secure due to its fluctuating valuation (Bentov, Lee, Mizrahi \& Rosenfeld, 2014). 
The Relationship of Online Discourse on the Values of Bitcoin and Ethereum

\subsubsection{Valuation and Influencers of Value}

Unlike traditional forms of currencies, many of whom are subject to the control of a centralized form of government, Cryptocurrencies are not subjected to the specific rules of one official entity, and similarly, each recognized Cryptocurrency has value that can be translated to traditional forms of currencies (Martucci, 2018). As an intangible entity and form of investment, the valuation of Cryptocurrencies occurs according to several different factors. Currently, the approximate eclectic value of all Cryptocurrencies rests upon seven billion US Dollars, shifting from day to day, in some cases with sharp rises or steep falls. As such, research has yielded that there are three major factors in determining the values of these currencies; competition amongst producers of the specific currency, efficacy of currency production, and finally the intricacy of the blockchain algorithm used to produce said currency. Thus, these three factors determine the traditional economic value of each coin, or the "coin to dollar value". However, this paper aims to specifically address the shifts in the value of these currencies according to online discourse. Meaning, that technological and production elements determine the traditional conversion value, whereas online discourse influences the shift in market value (Hayes, 2017).

The market of Cryptocurrencies is simultaneously very unique and different from different fields of investments due to the unique traits and influencers it has. Similarly, to the traditional large stock markets such as the New York Stock Exchange (NYSE), the influence does not happen in the traditional physical and web environment, rather a unique mix of both (Tarasiewicz \& Newman, 2015). The majority of Cryptocurrency trade occurs across a number of specialty websites across the internet, and in many countries, there are physical "exchanges", in many of which the trading is conducted clandestinely due to the nations' attempt to limit this currency. The plurality of these physical locations however, simply providing a physical address for traders to perform the transaction of transferring their digital coin to a physical wallet, which is often a secure memory drive (Gorsline, 2018). As such, aside from the traditional supply and demand influencing the value of these unique investments, many other factors are important to consider, one of which is the online discourse surrounding the topic of Cryptocurrencies and their investment. Studies have correlated the technological aspect of prevalence of keywords relevant to Cryptocurrencies and their currencies in social media discussion to their respective shift in values. It was noted that recognition of search for Crypto values along with their discussion in social media has made them more prompt to the public, thus making the public more aware, leading to investment activity as a result (Li \& Wang, 2017). This 
The Relationship of Online Discourse on the Values of Bitcoin and Ethereum

paper aims to solidify the notable correlation between online discourse and the fluctuation of Cryptocurrency value, specifically Bitcoin and Ethereum, which coincides with the rationale of many theories and models of communications.

\subsubsection{Theories and Models of Communications}

The field of communications is a very diverse and aged field with studied effects in other aspects of society such as politics, behavior, cognition, and the economy.

Historically, the search for information on social platforms, specifically physical, traces back to the town center for social gathering with a town crier notifying the residents of previous and impending events. Resultantly of the developments over time, social scientists largely in the mid- $20^{\text {th }}$ century have sought to understand the extent of the effects of communications, and thusly have tied the results to said fields using both qualitative and quantitative research and experiments. As mentioned previously, one of the key theories of communications, Theory of Technological Determinism, it is arguable that the prevalence of contemporary technologies is the key factor in delivering Cryptocurrencies as one of the leading fields of Fintech throughout the past decade (Marx \& Smith, 1994). Consequently, many large fields of studies are subject to studies designated to fully understand the extent of the effects that the media has upon them. Many of said studies have been orchestrated to examine the different the effects of the media, specifically of mass communications and small-scale communications. Understanding the content and its context is imperative to fully comprehending the magnitude of the media's effects upon the public, and on occasion regarding specifically susceptible groups such as children (Bryant \& Miron, 2004).

As such, one of the most referred to studies in communications regarding influence by the media is the 2-Step Flow of Communication Theory. The basis of this theory is that consumers are more affected by media content based on their relationships with others. In a study conducted regarding this theory, voters were cataloged according to the following labels based on their exposure to the media and interpersonal communication; Opinion Leaders, Waverers, Converters, and Crystallizers. Paul Lazersfeld, a prominent $20^{\text {th }}$ century American sociologist, conducted this study focusing on candidate speeches observed by the public through mass media, and based his conclusions on the effects of the media and interpersonal communication (University of Twente, 2015). His findings concluded that Opinion Leaders were individuals who decided very early who they would vote for without changing their minds, tending to be more exposed to the media than 
others, and had the ability to sway the votes of others. The nature of this relationship is characterized by the media awareness and involvement of these individuals, with Opinion Leaders becoming the leading influencers of people's opinions due to their perceived expertise correlated to their media awareness on the relevant topics (Lazersfeld \& Merton, 1948).

Similarly, Coleman et al.'s Drug Study was another experiment, strengthening the assumptions established by the 2-Step Flow Theory. In this study, researchers examined the effects of Opinion Leaders on their followers by examining the adoption of new drugs among doctors. The findings of this study concluded that the most important factor for physicians adopting a new drug was the extent of integration of that drug in the medical community. This established that interpersonal relationships outweigh the influence of media in providing information, as physicians relied on others' adoption of the new drug before concluding their own stance. The criticism of this theory resonates from the fact that the effects of the media are not always linear and that it often overlooks the effects upon the Opinion Leaders themselves (Coleman, Katz, \& Menzel, 1957). Within the context of social media, and social networking sites, it was demonstrated that one's peers can influence perception regarding scientific information (Hayat, Hershkovitz \& SamuelAzran, 2019), health information (Hayat, Brainin \& Neter, 2017), purchasing intentions (Hayat \& Hershkovitz, 2018), and exposure to new ideas in general (Hayat, Lesser \& Samuel-Azran, 2017).

Another equally important theory of communications attributed to the of Cryptocurrencies is the Diffusion of Innovations Theory. This theory appends the ideology of how new ideas and practices spread within and between communities and groups. One of the most important factors of this theory influencing the diffusion of a new technology or idea, is the time upon which it is spread among its potentially new adopters. Diffusion often takes an extensive period of time to transpire, and there are many individuals, societal, cultural and technological factors affecting the pace and nature of the diffusion (Ardis \& Marcolin, 2017).

One of the most critical aspects of the Diffusion of Innovations Theory, is deciphering who are the users who adopt and evolve into traders of Cryptocurrencies. According to this theory, there are 5 classifications of the people who fit the mold of this theory in adopting new technologies and trends; Innovators, Early Adopters, Early Majority, Late Majority, and Laggards. Innovators are pioneers who quickly adopt and use the new technology. These are individuals who are most keen on trying new ideas, accept 
possible risks, and hold more diverse relationships, while often maintaining relationships with other innovators. Early Adopters are often more integrated into local social structures. They often hold the position of individuals who are consulted with prior to adopting a new idea, and often characterize opinion leaders as they symbolize the notion of role. Individuals defined as the Early Majority mostly adopt new ideas immediately before the masses, yet rarely hold positions of leadership. This category refers to individuals who require time for consideration prior to adopting a new idea. Members of the Late Majority are mostly characterized by their skeptical disposition regarding new idea. They only tend to adopt new ideas after the average user or person, whereby the adoption results from necessity derived from economic or peer pressure. Lastly, Laggards are the final individuals to adopt an innovation, are characterized towards preferable orientation to the past or tradition, captivated by their suspicion towards new ideas (Lundblad, 2003).

Per the Diffusions of Innovations Theory, it is critical to analyze the different classifications of investors of Cryptocurrencies, in order to fully evaluate who are the people who joined the Fintech trend, at what points in its time they invested, while importantly noting the point of release, rises, and drops in the values of the currencies. Innovators would be most fittingly described as the individuals whose interest was piqued upon the release of the Bitcoin in 2008, and in the immediate time frame began purchasing currency and in fact becoming the first investors and traders of Cryptocurrency. Taking the preliminary risks and dangers of vesting their equity into the uncharted territories of the unfamiliar Fintech, these individuals not only took the largest risks, but also accumulated the largest rewards in the form of ROI (return on investment).

In the years following the conception of Bitcoin until approximately 2014, it can be argued that the characterization of those traders would be best defined as Early Adopters. This is the most fitting definition regarding the individuals of the aforementioned timeline, due to the gradual rise in value, Bitcoin still had not accumulated stability in the fluctuation of its value, coupled with reinsuring worth of currency. At this point, the Cryptocurrency appeared still somewhat unpredictable to the general public, however with a trend of rising value leaping from the consistent valuation in Bitcoin's initial months of existence from several cents to approximately $\$ 850$ (Sundararajan, 2018). During this period, more information and knowledge was accumulated by these investors, giving them the position of those who are often relied and turned to for information, yet not having been part of the initial wave of investment. Thusly, these investors did not sustain the 
initial risk of investment upon the conception of Bitcoin, yet, joined very early nonetheless while the currency was still unsubstantiated as a "more stable" investment.

The Early Adopters of Ethereum (ETH) and Bitcoin (BTC) are one of the most critical groups to evaluate regarding the influence upon the fluctuation of currency value, due to their roles as Opinion Leaders. In the context of online discourse, these are the individuals who are most involved in online chatter regarding the subject of Cryptocurrencies, and their opinions are most sought out and influential regarding investment. Thus, this group of investors may be considered the most influential regarding the valuation of the currency. The opinions of the Early Adopters are those which sway the investment habits of the Early Majority, members of the Late Majority who invest, excluding Laggards, who are least likely to invest in such a cutting-edge technology and economic trend.

An alternative theory of communications enhancing the clarity of the relationship of the media and Cryptocurrencies, is the Agenda Setting Theory. In its very core, this theory proposes that that although the media may not tell people what to think regarding certain issues, it does dictate to people what to think about, thereby setting the agenda for the way that people think (McCombs, Shaw \& Weaver, 2013). One of the pillars of this theory dates back to a study conducted in 1922 by political commentator, Walter Lippmann. In his research, Lippmann asserted that the media creates a "pseudoenvironment" which is so dominant, that it has larger impact compared to the "realistic environment". To this extent, he concluded that the "realistic environment" is too extensive for the new media to capture, and therefore are not able to capture the precise reality of the entire world. Therefore, the media selectively chooses what to focus on, thereby creating a media environment which is not accurately representative of the "real environment", hence creating a "pseudo-environment" (Park, 1923).

Correlating the Agenda Setting Theory to the field of Cryptocurrencies, one may say that in recent years, the extensive media coverage that this unique field of investments has received has yielded tremendous influence on the fluctuation of value. One can argue that in recent years, specifically from 2014 onwards, the media has given an increased focus upon Cryptocurrencies, with Bitcoin specifically as one of the leading currencies receiving extensive media coverage. Resultantly, we see a trend of sharp rises in currency value dating from 2014 due to increased investment activity related to the extensive media coverage given. Thus, according to the Agenda Setting Theory, the media has "given" the general public the topic of Cryptocurrencies to focus on in recent years, resulting in more 
and new investors, along with more equity traded in this field (Cheah \& Fry, 2015). Furthermore, upon the proven success seen in traded value of the Bitcoin, Altcoins such as Ethereum have become more prevalent in their discussion in the media. Resulting from their piqued recognition by the media, there has also been a visible spike in the value of Ethereum in recent years in addition to the more popular Bitcoin (Phillips \& Gorse, 2017).

According to the studies of Aral, Muchnik, and Sundararajan, one of the strongest indicators of affiliation and social influence relates to the idea of homophily. This term refers to the phenomenon whereby people are most likely to associate and develop ties with other individuals most like themselves. Thus, in the context of the users frequenting boards, forums, pages, and online content relevant to the Cryptocurrency market, it is presumable that they share similar traits both in interest and content, attracting them to the same content, and more importantly to one another. This ideology is critical to analyze and comprehend, as it can be a strong indicator regarding the definition of the population who are both interested and specifically trade within the realm of Cryptocurrencies. Furthermore, within their study, Aral, Muchnik, and Sundararajan concluded that people are more likely to listen to or be influenced by their friends than others. This notion of influence is imperative to address and correlate to the myriad of possible explanations to the fluctuation of Cryptocurrencies, by highlighting the effect of social influence as one of the most powerful reasons for transactions. More specifically in the context of influence, "...how the behaviors of one's peers change the likelihood that (or extent to which) one engages in a behavior." The study conducted to attest to this phenomenon regards the dispersion of contagions through social networks by examining the elements that propel this occurrence. One of the largest deviations from this study regards the notion that friendships are not random, whereas the exposition of certain users to certain content surrounding Cryptocurrency online can be. As such, the plethora of different online platforms providing as sources from information for Cryptocurrency also pose as the strongest possible influencers whereby not only are the users subjected to the opinions and predictions of seeming Opinion Leaders, rather also their own friends serving as greater influences in accordance with the aforementioned theory (Aral, Muchnik \& Sundararajan, 2009).

\subsubsection{Literature Review}

One of the strongest indicators or factors affecting investment patterns among people results from the studied phenomenon of social influence. This occurrence remains 
constant and true even within investment patterns, where individuals will tend to rely and appropriate investment behaviors of their successful peers. In business terms, the trend of mimicking investment patterns of successful counterparts is known as "follow-the-leader behavior" (Mai et al., 2015). This inclination is extremely familiar to the studies and conclusions of the 2-Step Flow Theory, embodied by people defined as Opinion Leaders and their influence among others as aforementioned.

By examining investment patterns of hedge funds and mutual funds, it became apparent that due to the visible behavioral patterns of investors, mutual fund investment activity was visibly influenced by hedge fund investment activity. Oppositely, hedge funds did not exhibit traits of influence in investment activity by mutual funds. It was concluded that due to the reliance of investors of mutual funds upon the activity of hedge fund investment resulted in steep price shifts. Thus, it was tangible to conclude that the reliance of investors upon the investment behavior of others can lead to market destabilization due to a shift in equity vestment. Jiao and Ye who conducted thorough research regarding investment trends were able to assume such an important relationship between investment firms who assumed the same patterns of investment based upon identifiable communication practices signaling the encouraged investment. Due to the awareness of these firms regarding the perils of unpredictable trade habits of others, there became an emergence of codependency towards "savvy" hedge fund managers who exhibited their prowess in equity management. This becomes extremely representative of the aforementioned "follow-the-leader behavior", along with relevance to the Two-Step Flow Theory of Communications. This study is very indicative regarding the patterns of behaviors of people, specifically in the world of equity, with different studies of equal depth examining this phenomenon through the platforms of the online world. More importantly, the investment behavior deduced by examining the influence upon online platforms is indicative of the same trends seen in the Cryptocurrency economy (Jiao \& Ye, 2014).

More directly related to the assertion of this piece, Peng Xie researched the parameters of social data, specifically social media influencing digital currencies in a holistic fashion. This research was conducted in an attempt to isolate the information relevant to the influences upon value, specifically exerted from social data, from the surrounding "noise" which may influence, yet is unrelated to the topic at hand. Specifically in this study, the data collected regarding Bitcoin value variability by employing empirical research methods exhibited that discussion emerging from extremely tightly knit social 
networks are in fact less predictive of future returns, this is resultant of "information free riding" (Xie, 2017).

Thus, the abundance of investors who absorb the information passively without actively contributing to it, influence the market movements in a fashion that is less predictive according to the discourse. Despite the lack of predictability seen in Bitcoin from this research, data extracted from social media does indeed indicate critical information in understand the different players and the degree of their influence. For example, information of tangible importance has a higher likelihood of sharing by very active users who tend to engage in discussion. Secondly, there is visible motivation to posting on social media, leading to influence upon user posting habits. For example, users will be more motivated to post and share content in certain types of social media groups for the reward in the form of Likes, Shares, etc. Unfortunately, these incentive-based social media platforms contributed to data of different qualities due to the motivation of the users for reward. Additionally, the more active users of social media provide less accurate data compared to the less active users. The reduction of rewards upon reaching "higher level badges" coupled with the increase use of social media for social purposes only, suggest additional "noise" in posts by the more frequent posters. Thus, it is concluded in this piece that different types of social media users classified by their frequency of posting can contribute to the accuracy of prediction of Bitcoin value changes (Xie, 2017). 


\section{Methodology}

As in all research methods, specifically empirical as this study, one must designate a specific population to assess in order to fully understand the relationship of online discourse upon Cryptocurrencies. In order to evaluate understand the relationship of online discourse with the fluctuation of values of Bitcoin and Ethereum, one must evaluate a more specific group to analyze the correlation of effects. In this research paper, the specific sample representative of the population in this study is the online discourse surrounding Ethereum (ETH) and Bitcoin (BTC). In order to evaluate the trends in the behavior and quantity of online discourse prior to a significant drop in Ethereum \& Bitcoin, several precise steps must be taken. It is notable that by using the tool used for this study, Buzzilla (http://www.buzzilla.co.il), that only public discourse is taken into for account for the public discourse. The designated sample was chosen due to the fact that Bitcoin was the initial Cryptocurrency developed, dating to 2008 as mentioned previously, evolving into the most valuable currency in the Crypto-economy (Lee, 2014). It is also one of the most recognized names of the industry, providing more likelihood for detection of online discourse on the subject. Ethereum was chosen as the secondary Cryptocurrency for analysis due to its popularity and arguable recognition as the second leading currency in the Crypto-economy.

The main tools used throughout this study are data collection and reference oriented. Buzzilla, a tool for examining both quantitative and qualitative values, is able to examine online discourse throughout a myriad of online platforms for the specific values searched. It is notable however that this critical tool is only able to assess public discourse. Different social media platforms such as Facebook and Twitter, are among those being analyzed by this tool along with blogs, forums, and other sources of viable information. CoinDesk (www.coindesk.com), a website used to trade and source information regarding the different Cryptocurrencies. This website serves as a market place similar to a stock exchange, however for the purposes of this study, it was used as a reference to observe the variations of values within the studied currencies. Using this website, it is possible to view the exact value at specific dates and time frames of the desired currencies, and thus 
compare the movement of that period according to the contemporary discourse on online platforms.

Lastly, the procedure was one of the most critical aspects to organize and strategize in a detailed fashion, in order to accurately extrapolate the most significant data needed to examine the hypothesized correlation between online discourse and the movement of Bitcoin and Ethereum values. Firstly, it was imperative to designate a point of reference for the values of the Cryptocurrencies examined. This point of reference pertains to a specific exchange website, as different sites may deviate in their values based on how upto-date they are or other factors. As such, it was important to examine a pre-determined time frame, focusing on sharp rises and falls in the values of Bitcoin and Ethereum, and investigating the online discourse regarding these Cryptocurrencies preceding these shifts.

Another critical part of the process was highlighting the most relevant platforms upon which the discourse transpired. As an economic entity, relevant content posts on a variety of platforms ranging from social media pages to relevant blogs, however it was important to attempt to conclude not where the most discourse was taking place, rather, which was the most influential. Lastly, using Buzzilla to scour the web for relevant data unveiled a significant issue in content found. Simply searching according to the full names of Bitcoin and Ethereum provided a prolific amount of results, however it became apparent with time that adding the ticker symbols, BTC and ETH respectively, delivered additional opportunity. This was a critical conclusion as it is suggestive that certain communities may want to maintain a closed circle of information within the confines of their own members.

Specifically, as part of the process of examining these effects upon Bitcoin and Ethereum, it was critical to pinpoint at least three specific dates at which a sharp rise or fall unraveled within the market. Beyond the significance of the drops, it was important to attempt to isolate the instances in order to prevent biases that may have been ongoing specific to the same relative time period. Thus, three such points were also selected according to the comparative values of these currencies to the other points chosen for comparison. However, it is imperative to not that these points of reference chosen would only be relevant within the span of the previous two years due to the limitations of the data collection tool used, Buzzilla. The website used to source the information regarding the shifts in value of the currencies researched, is not limited within the scope of the same range Buzzilla is. Regarding Ethereum, CoinDesk is able to portray the value dating to September $1^{\text {st }}, 2015$, and July $18^{\text {th }}, 2010$ for Bitcoin as seen in Figure 1 and Figure 2 respectively (Sundararajan, 2018). Thus, the arbitrary dates selected for reference of 
Ethereum are; June 15" 2017 (“ETH 1"), January 1 $1^{\text {st }}, 2018$ (“ETH 2"), and April 1 $1^{\text {st }}, 2018$ ("ETH 3"). For Bitcoin the relevant dates selected are; November 10 $10^{\text {th }}, 2017$ ("BTC 1"), December 7"h 2017 (“BTC 2”), and February 5"th 2018 (“BTC 3”).

\begin{tabular}{l|l|l|l|l|l|l|l|l|l|l|l|l|l|}
\hline $1 h$ & $12 h$ & $1 d$ & $1 w$ & $1 m$ & $3 m$ & $1 y$ & All
\end{tabular}

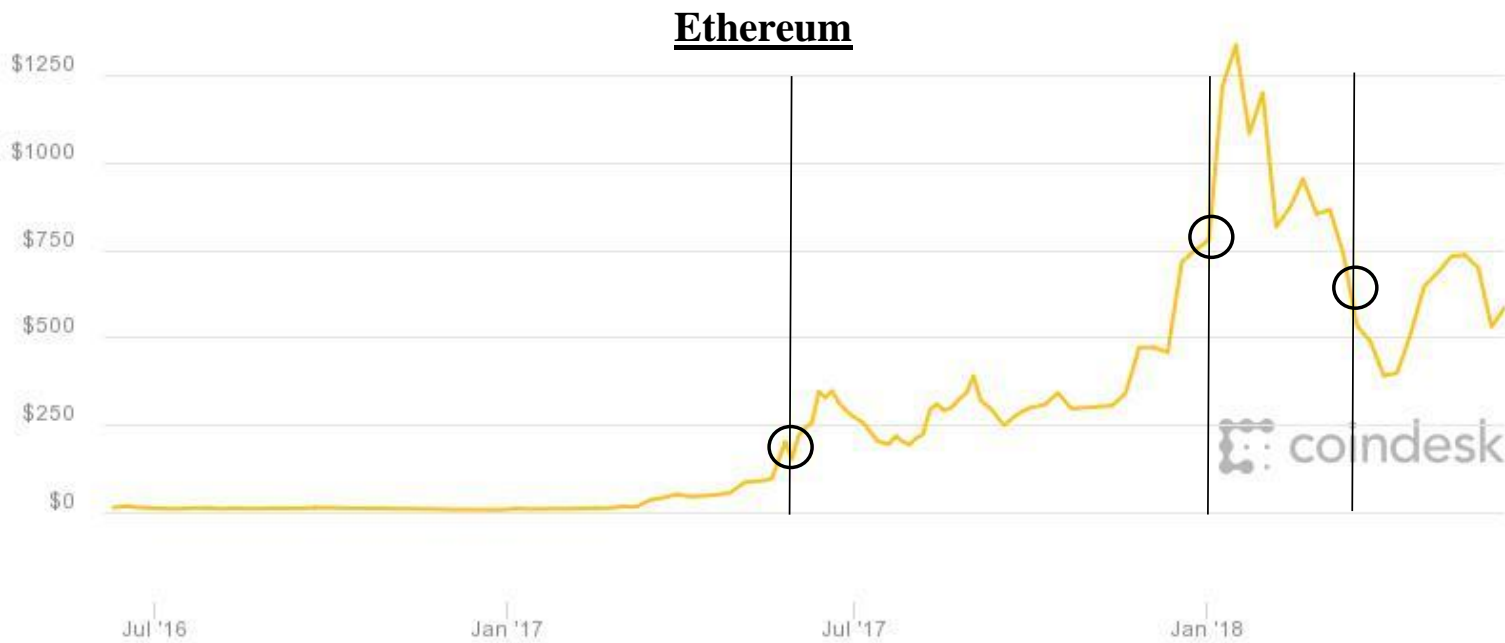

Fig. 1

Bitcoin

$\$ 15000$

$\$ 10000$

Fig. 2 


\section{Results}

When examining the patterns of change within the valuation of Ethereum, one of the preliminary points of change viewed in the market occurred around the date of June $15^{\text {th }}, 2017$. This is the point in which the Cryptocurrency begins a sharp ascent from values in the low \$200 range quickly towards the mid \$300-dollar range and jumping exponentially afterwards (Godbole \& Sinclair, 2018). By using the base parameters in Buzzilla for data collection of Ethereum, searching in a three-day range of the selected date, meaning beginning the data collection at the day before the chosen date and ending on the following day. This search was also conducted by using a basic search according to the currency's name and ticker symbol, Ethereum and ETH respectively. The quantitative results were as follows, $59 \%$ of the online discourse on this subject was attributed to the keyword "Ethereum", while the remaining $41 \%$ belonged to the ticker symbol searched. Additionally, 450 discussions were conducted upon Ethereum and 309 held for ETH as seen in Figure 3 (Buzzilla, 2018).

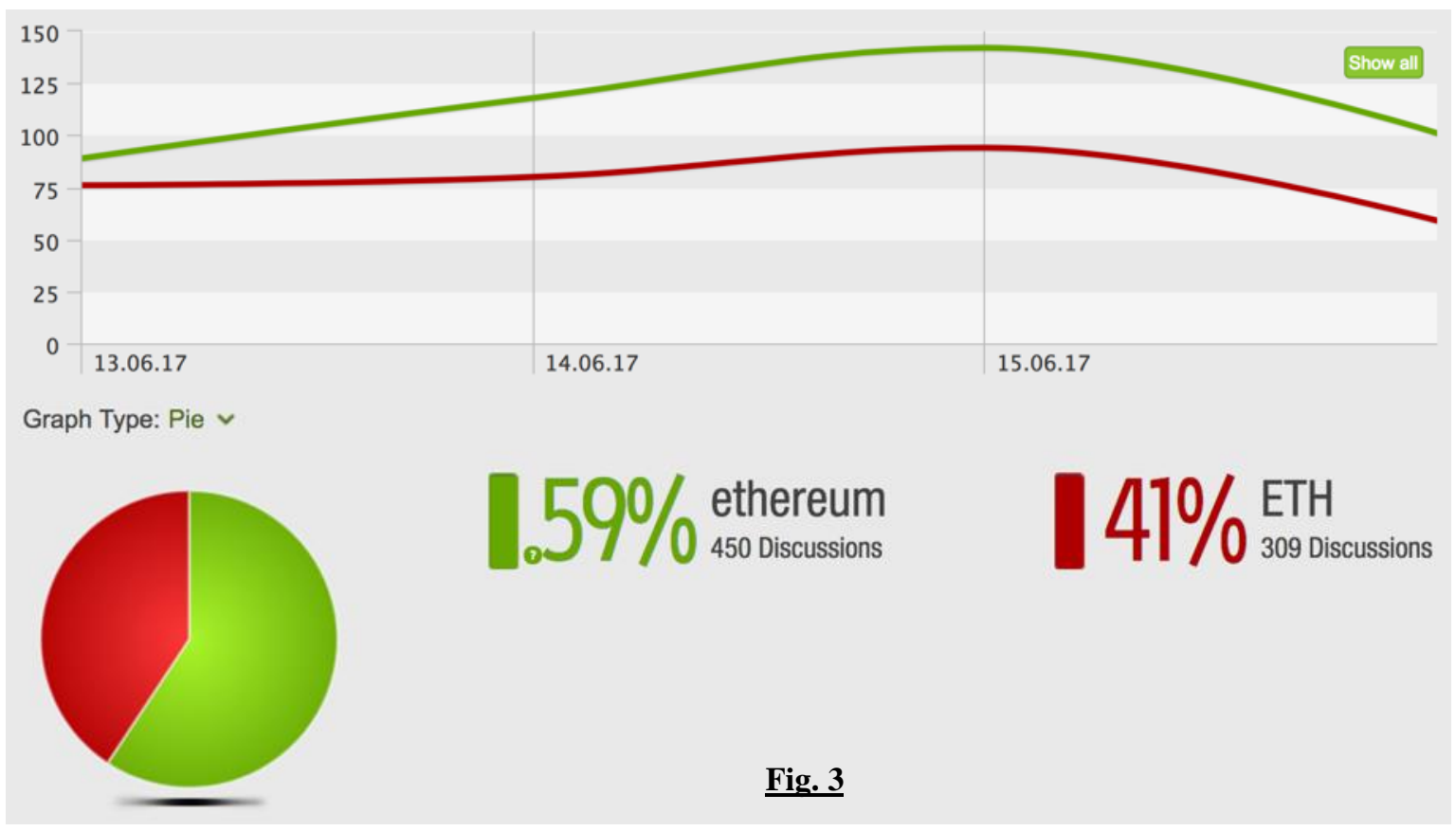

Regarding the user segmentation of the posted content for Ethereum on the inspected dates, two users appeared as the most frequent and active participants both as contributors and responders to relevant content, “Anonymous" and "Tyler Durden". Both pseudonyms for users, "Anonymous" does not provide critical data as it can be attributed to any myriad of users who choose this as their nickname on the online platforms, which is 
likely to be high. "Tyler Durden" however, incidentally the name of one of the movie Fight Club's protagonists, participated in 3.22\% (15) discussions, while "Anonymous" participated in $16.52 \%$ (77) discussions. For ETH however, "Anonymous" participated in $51.23 \%$ (166) of discussions, while "Tyler Durden" participated in $4.01 \%$ (13) of discussions. In terms of user segmentation, "Tyler Durden" proved to be the most influential participant of discussion within the dates of June 14th-16th, 2017, with 755 interactions and 611 shares. (Buzzilla, 2018) The majority of online discourse surrounding the topic of Cryptocurrencies is seen as taking place upon forums such as on Tigerdroppings, with frequent posters similar to "Tyler Durden", voicing their opinions and steering the investment behavior of members of the forum. Thus, we can assume the influence beyond the "influence" score given by Buzzilla, but rather to the 2-Step Flow Theory, classifying the user as an Opinion Leader. Thus, the nature of the discourse on the forum relates to the "prophecy", where the prediction of the currency was far lower than its actual preperformance, thus with the more frequent posters urging other members of the forums to invest ("Official CryptoTalk Thread", 2018).

Surrounding the fiscal activities of January 1st, 2018, the scope of dates examined ranged from December 31st, 2017 to January 2nd, 2018. During this timeline, 69\% (559) discussions held were on the topic of Ethereum while the remaining 31\% (245) discussions were on the subject of ETH as seen in Figure 5. The quantitative data yields critical information surrounding both the discourse specifically during this time period as the spike in value possibly due to the new year. During this time period, a rise in value is seen from approximately $\$ 750$ per coin, to over $\$ 1,200$ over the course of the following two weeks. As such, an important question is asked as to what the nature of the discourse was in order to influence the investment patterns so dramatically (Godbole \& Sinclair, 2018). Regarding the user segmentation of this period, the most active users with the keyword "Ethereum", were "ZTwithDaBeatz" and "cbs8", involved directly in $4.52 \%$ (30) of discussions and $3.02 \%$ (20) of discussion respectively (Buzzilla, 2018).

The site segmentation of discourse relevant to "Ethereum" was attributed with approximately $30 \%$ of the data towards Facebook and Twitter, whereas for "ETH", the overwhelming majority of discourse took place on Facebook, 4chan, and Reddit. This segmentation provides critical insight to the patterns of social influence as the more fiscally savvy and involved users go to social forums more similar to blogs where ideas and predictions are shared opposed to traditional social media platforms. One explanation to consider may be the notion that these forums provide a welcoming platform for 
duplicity of knowledge and sharing, whereas social media may be increasingly close-ended and at times one way to voice an opinion and not host a discussion. The user segmentation of the most involved users relevant to discourse containing "ETH" proved to be "Anonymous" and "cbs8", with 55 or $21.24 \%$ of discussions and 10 or $3.86 \%$ of discussions respectfully. While maintaining the assumption that "Anonymous" is a wide representation of many users with the same general pseudonym, "cbs 8 " is a very important user to regard. As a very salient user in both keywords searched, it can be assumed that the user is very involved in the field of Cryptocurrencies, specifically relative to Ethereum (Buzzilla, 2018). Regarding the site segmentation, it is critical to examine the nature of discourse on the forums such as 4 chan, with immediate discussion regarding the projection of valuation ascension ("ETH \$1K Thread", 2018).

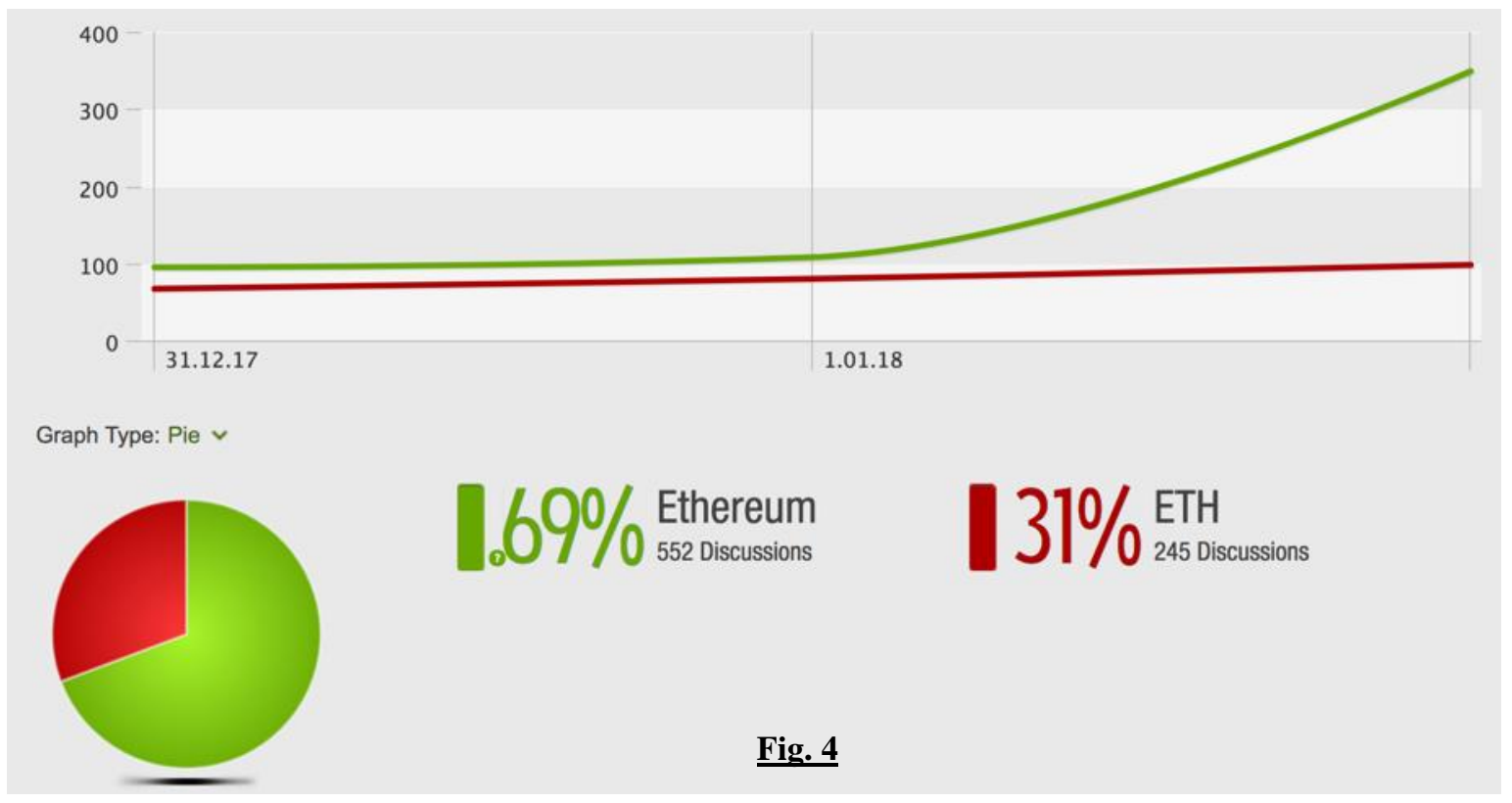

Lastly in the context of Ethereum, the date range of March 31st through April $2^{\text {nd }}$ of 2018 was researched in order to evaluate the movements on April 1st, 2018. The quantitative data regarding the keywords "Ethereum" and "ETH" yielded 44\% (193) of discussions or 56\% (243) of discussions respectively as seen in Figure 5. Primarily it critical to note this shift in quantity of discussion per these turns as it appears that over time users have become more fiscally savvy, partially in terms of the "critical" jargon used to find the important posts and forums. This can be correlated to the mass involvement of investors regarding information relevant to the recent tumble of the currency's value, which at this point had reached approximately $\$ 385$ when within the previous two weeks it was valued at nearly twice as much (Godbole \& Sinclair, 2018). Once again "Anonymous" and "cbs8" posed as the major users involved in the discourse regarding the keyword 
"Ethereum", however this time "cbs8" was superior to the former. Regarding the search of keyword "ETH" however, "TronSupportTeam" and "Anonymous" comprised 13.69\% (36) of the discussions and $6.84 \%$ (18) of the discussion respectively. Thus, the nature of the most influential content posted had begun to identify the plummet of Ethereum's value beginning to take place at this point. Furthermore, the site segmentation of the keyword "Ethereum" showed 12\% (26) discussions and 11\% (24) discussions emanating from Facebook and Twitter respectively. For "ETH" however, the collected data from the different platforms proved to be richer. $33 \%$ (88) discussions and 21\% (54) discussions originated from Twitter and Facebook respectively (Buzzilla, 2018). As represented by the data, one of the most influential articles revealed by the data titled "Why I Won't Buy Ethereum", can be correlated to the trend of users shifting their attention to the coin in terms of keywords and search additional to the trend of investment in their value (Noonan,

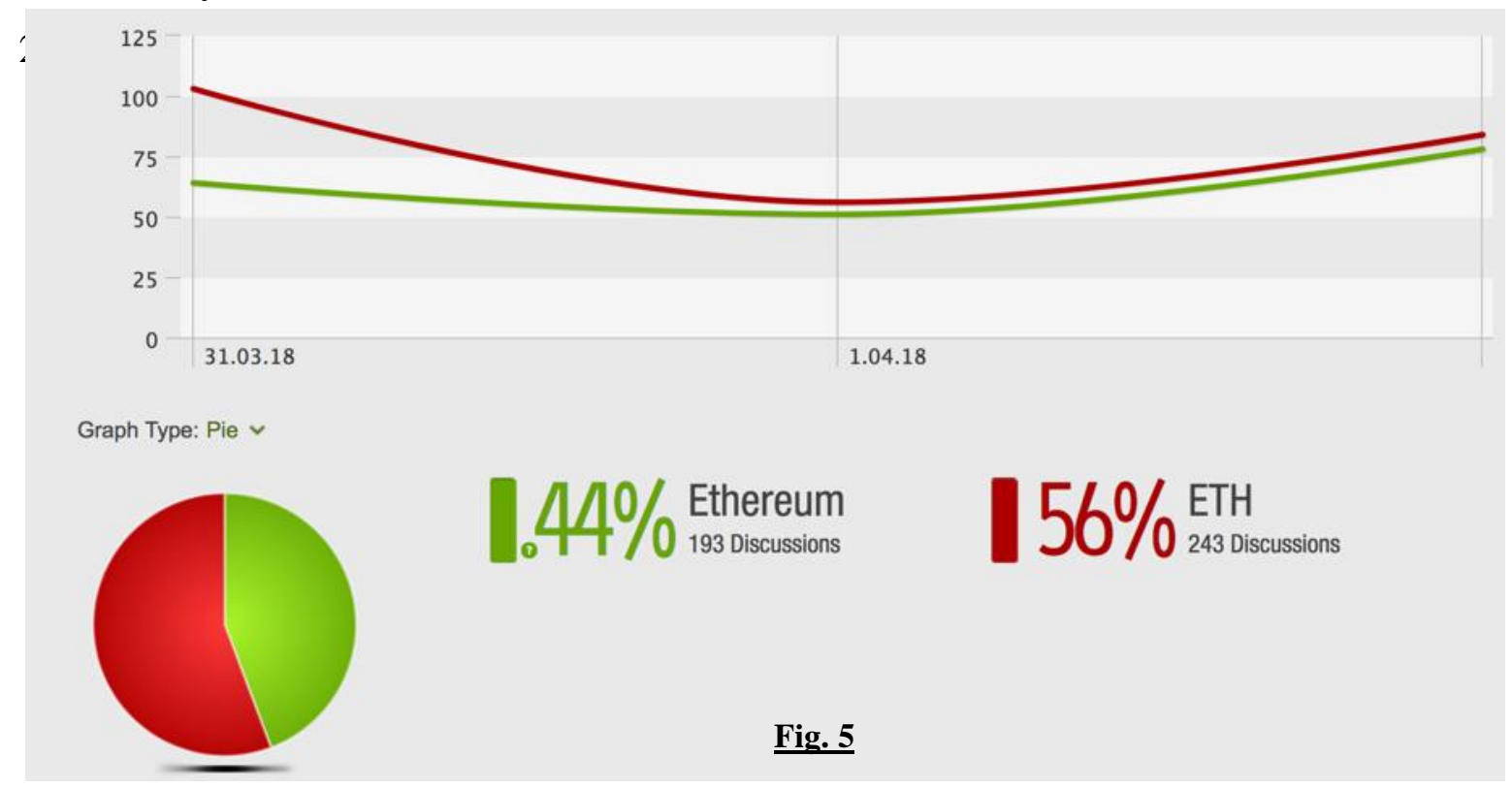

When examining the fluctuations of Bitcoin in comparison to Ethereum, the quantitative augmentation of value is notable, possibly due to the fame which the coin has accumulated over the decade of its existence. Within the time frame relevant to analysis by Buzzilla, one of the preliminary points of significant change in value ranges from November $9^{\text {th }}$ to November $11^{\text {th }}, 2017$, providing the depth in evaluating the significant shift occurring on November $10^{\text {th }}, 2017$. Throughout the aforementioned dates, it is notable that there is a significant change occurring during this period, with a decline in value preceding the exponential rise increasing over time (Sundararajan, 2018). As seen in Figure 6, the online discourse during the aforementioned dates, $83 \%(1,913)$ discussions were held regarding the keyword "bitcoin while 17\% (389) discussions were held 
regarding the ticker symbol "BTC". During this time frame, a sharp drop from approximately $\$ 7,500$ to $\$ 6,500$ transpired, with a preceding spike in discourse and resultant spike to suit. Regarding the user segmentation of this time frame, the following users participated in the online discourse with the respective amount; "handelsblatt.com" with 7.24\% (143) of discussion, "Anonymous" with 4.96\% (98) of discussion, and "Tyler Durden" who was very active in the discussion of Ethereum with $2.94 \%$ (58) of discussions. The site segmentation of this period was very consistent with the general ideology that the most influential discourse taking place would occur on social media with Facebook leading with 22\% (405) discussions and advfn.com, a financial brokerage website following suit with 12\% (219) of discussions (Buzzilla, 2018).

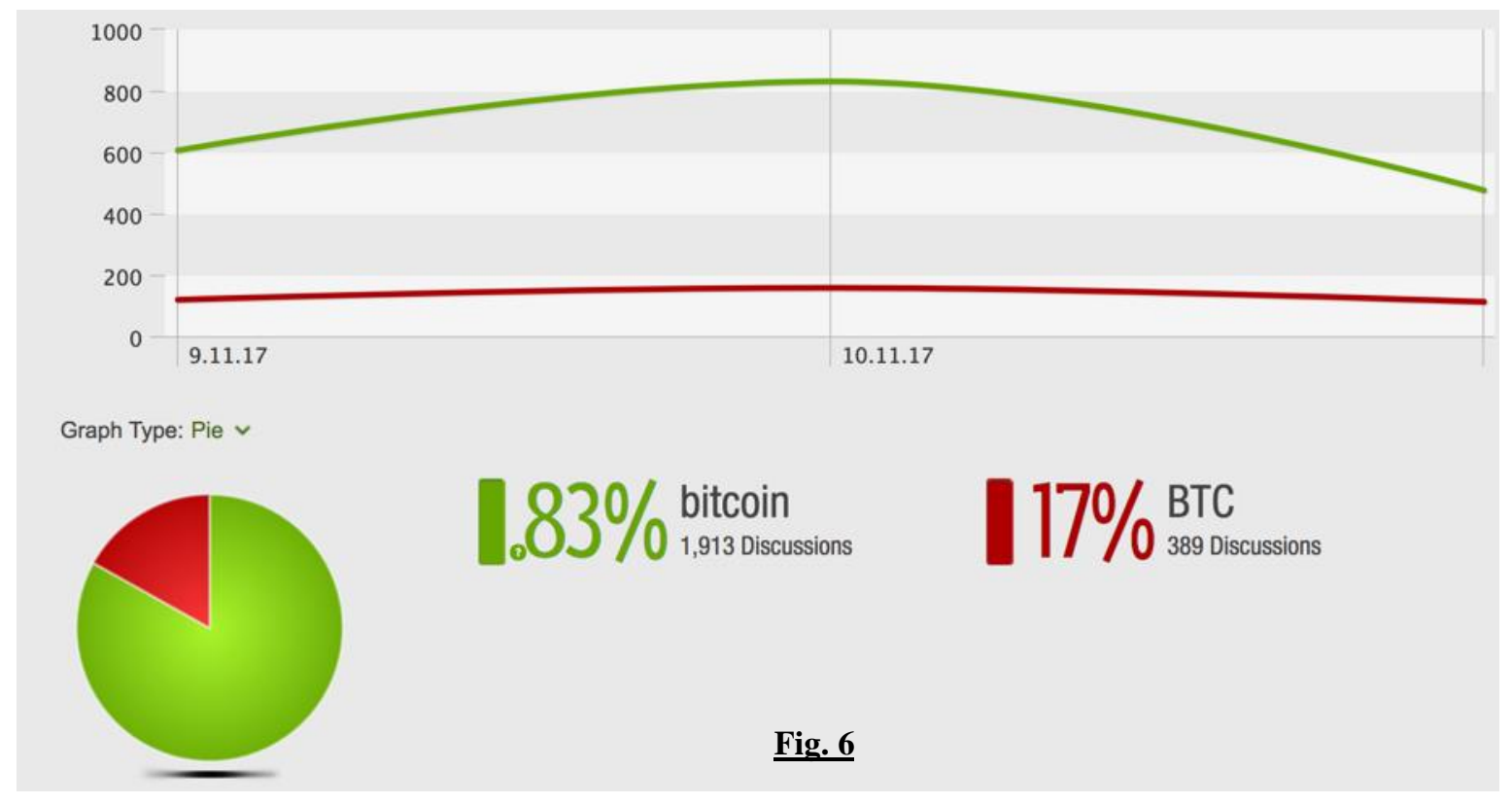

As shown in Figure 7, a period of significant changes in Bitcoin value began to take place between December 6-8, 2017, with December $7^{\text {th }}$ specifically proving as a tumultuous date with values climbing from approximately $\$ 12,000$ per coin to approximately $\$ 16,500$ (Sundararajan, 2018). Between these dates, we see an exponential rise in the online discourse with $88 \%(7,022)$ discussions held regarding the keyword "Bitcoin" whereas 12\% (994) discussions were held regarding the ticker symbol "BTC". In terms of user segmentation, $2.78 \%$ (201) and 2.63\% (190) discussions are attributed to the users "Anonymous" and "handelsblatt.com" respectively. Regarding site segmentation for keyword "Bitcoin", 16\% (1,003) and 16\% (1,002) discussions were held on Facebook and advfn.com, the social media platform and online brokerage website. Considering keyword "BTC", 22\% (218) and 15\% (147) discussions were held on Facebook and 4chan respectively. The data of collected during this period is notable due to the fact that the less 
fiscally advanced form of discussion posed as the larger subject of online discourse, perhaps indicating that the less economically involved were the catalyst for such an extreme change in the market (Buzzilla, 2018).

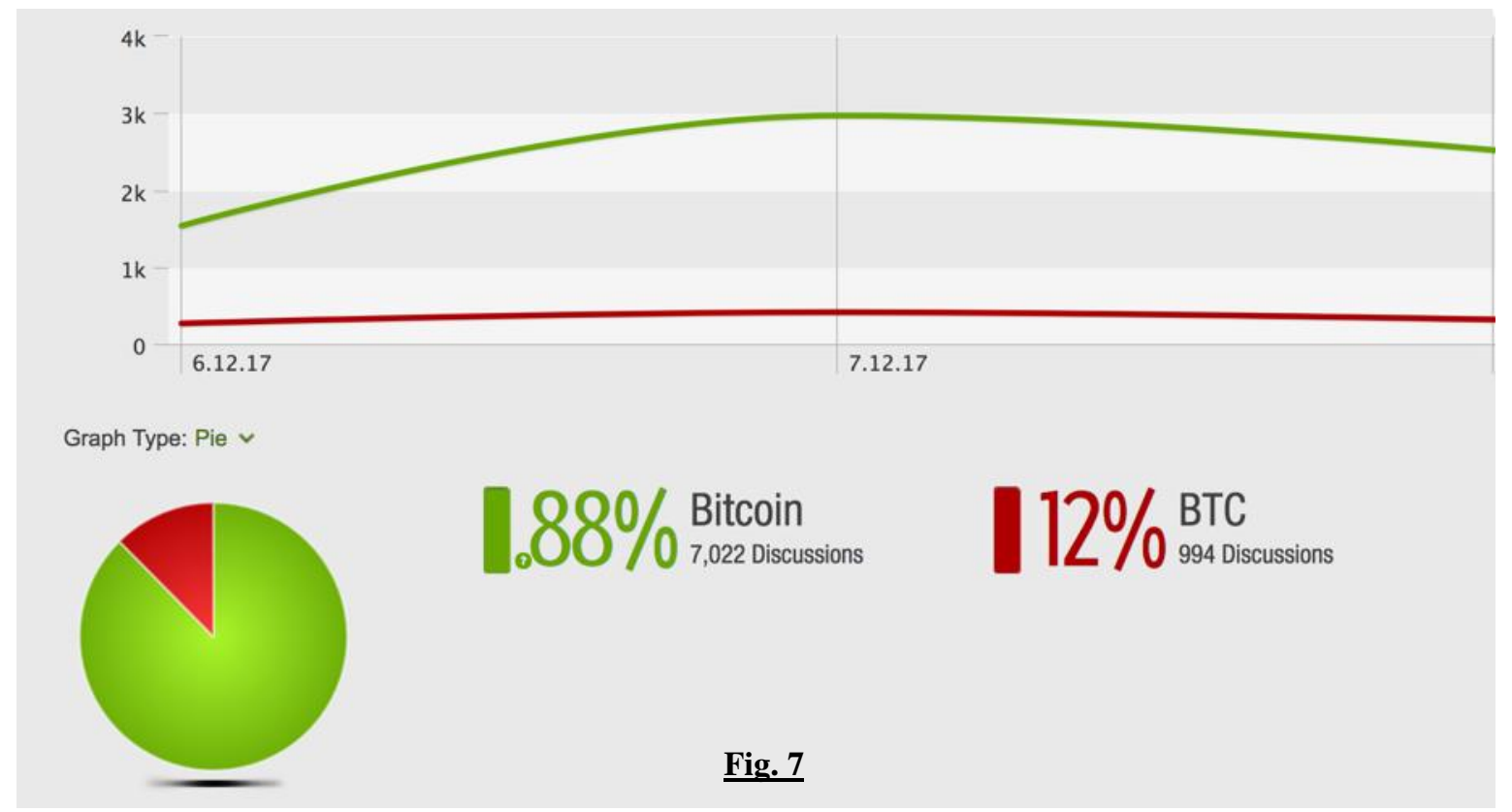

Lastly, Figure 8 indicates one of the more critical shifts in the recent period of the dynamic value of Bitcoin by considering the dates; February $4-6^{\text {th }}, 2018$, giving a powerful indication of the significant changes leading to and resulting from the events of February $5^{\text {th }}, 2018$, in terms of online discourse. During this timeline, there was a steep drop in value of Bitcoin from approximately $\$ 9,000$ to $\$ 7,000$ in the course of three days (Sundararajan, 2018). Thus, $88 \%(2,836)$ of discussions were held on the topic of the keyword "Bitcoin", while 12\% (539) of discussions were held on the topic of the keyword "BTC". Regarding user segmentation for the keyword "Bitcoin", "morningstar.com" and "Anonymous" were related to $3.55 \%$ (147) and $2.95 \%$ (122) discussions respectively. Regarding the user segmentation for the keyword "BTC", the pattern of consistent contributors continues with "Anonymous" and "Tyler Durden" relating to $13.5 \%$ (76) and 6.22\% (35) of discussion respectively. Similar to the site segmentation of keyword "BTC", the search for keyword "Bitcoin", proved Facebook and advfn.com to be the most popular platforms for discussion with 18\% (616) and 12\% (403) discussions held on these platforms. In terms of site segmentation for keyword "BTC", 23\% (129) and 16\% (89) of discussion were held on the most consistent platforms in regard to this research, Facebook and advfn.com (Buzzilla, 2018). 
The Relationship of Online Discourse on the Values of Bitcoin and Ethereum

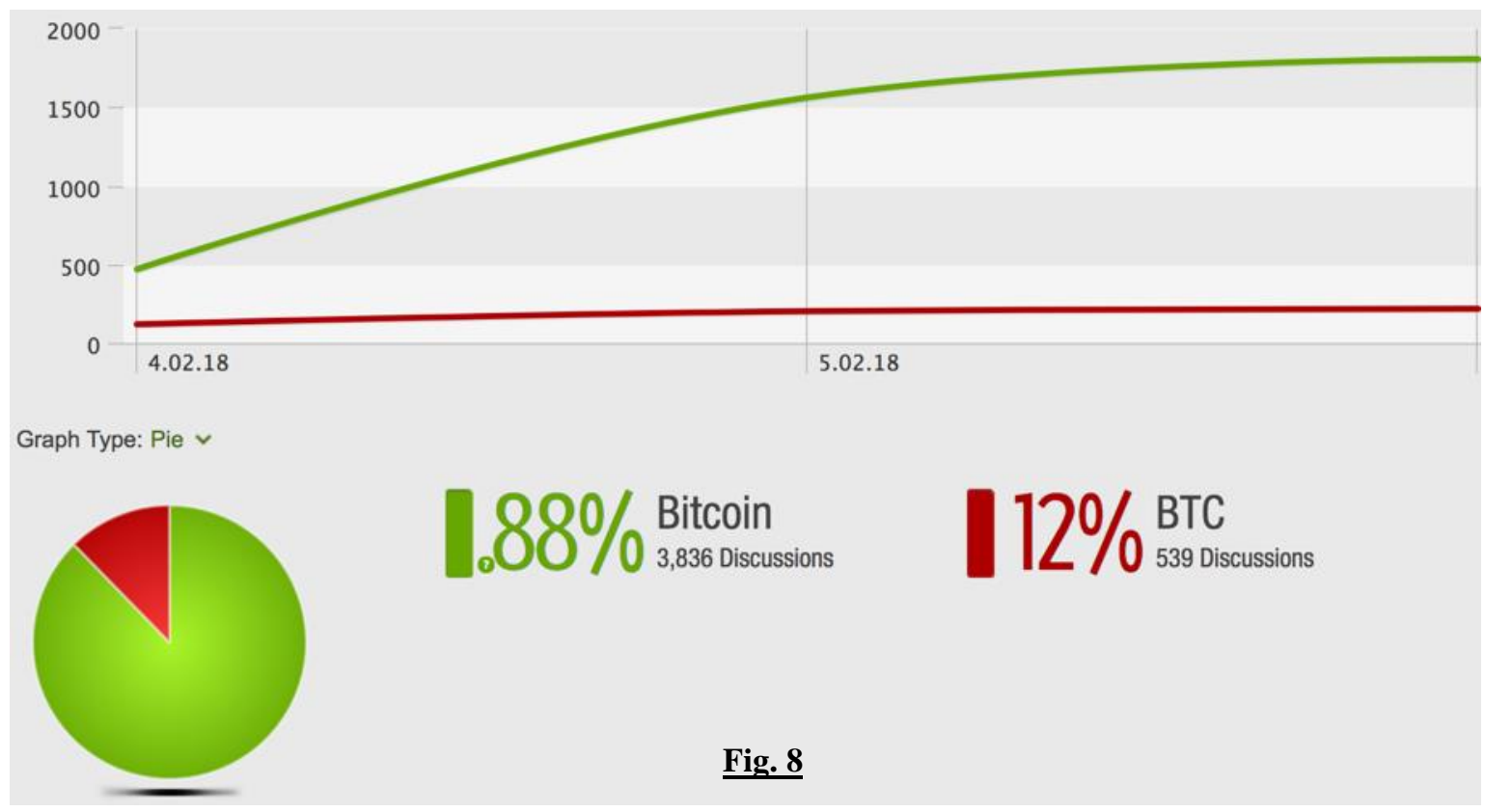

Another major indicator regarding the trends surrounding the online discourse on the topic of Bitcoin and Ethereum are the trending keywords as seen in Figure 9. Thus, the three studied dates per each currency were also analyzed according to the most prevalent keywords raised from online discourse. It is notable that the majority of results both in the search for both the full names of the currencies and their ticker symbols yielded what would seem as an abundance of general queries. For example, a plurality of terms such as "digital currencies", "digital asset", "virtual assets", and many others became a common result of the analysis. However, interesting results from the time frame of "ETH 3" indicate that with the maturity of the currency and market, users have understood the implied relationship between Cryptocurrencies and social media, beyond one serving as a point of information for the other. From "ETH 3" for example, the keywords "social media", "March 28 $8^{\text {th" }}$, and "March 29 $9^{\text {th" }}$ became a frequent subject of online discourse. Thus, it is assumable that traders were either scouring the web for Cryptocurrency advice and information on social media or were evaluating the content of social media during the time frame as it occurred. For Bitcoin, as the currency is far more popular and retains a higher value, thus it is understandable that it commands different keywords from online discourse. One of the more notable trends in the online discourse surrounding Bitcoin is the prevalence of content relating to content of behavior with keywords such as "buy sell" and "coming days" seen in the searches from "BTC 2". This leads to the hypothesis that traders are searching the web, specifically social media platforms and blogs for information to absorb or contribute to, thus influencing the investment behaviors of themselves or others (Buzzilla, 2018). 
The Relationship of Online Discourse on the Values of Bitcoin and Ethereum

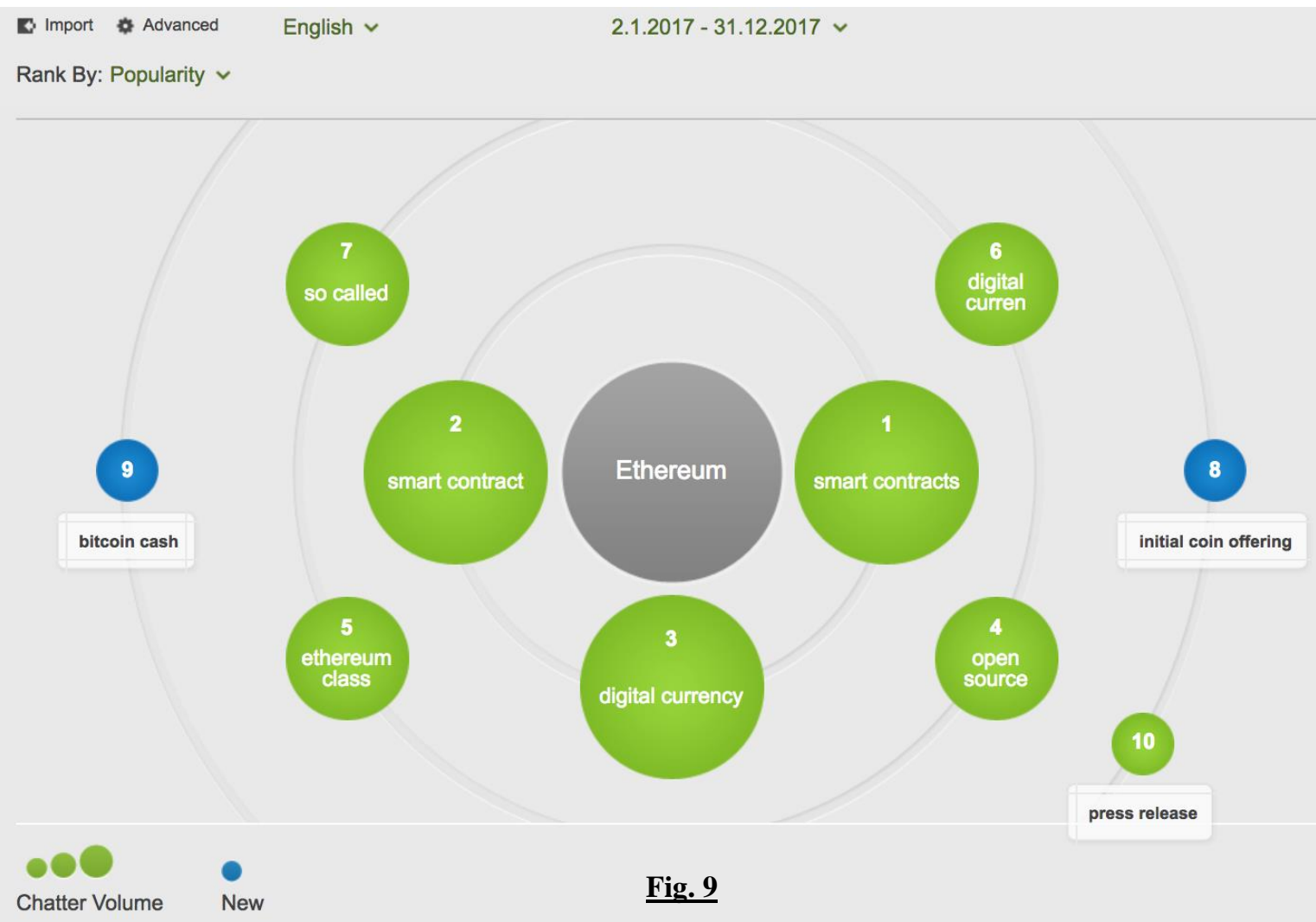


The Relationship of Online Discourse on the Values of Bitcoin and Ethereum

\section{Discussion}

When examining the turning points in the most powerful Cryptocurrencies, Bitcoin and Ethereum, it is imperative to consider all of the influential data extracted in the context of online discourse within this research paper. With the abundance of content online in the regarding Bitcoin and Ethereum, it is critical to understand upon which types of platforms and specifically upon which websites the online discourse takes place in the highest quantity and of which nature. The data extrapolated for Bitcoin using Buzzilla indicated that the majority of online discourse surrounding the Cryptocurrency, Bitcoin, was held on the most popular social media platforms, whereas the comparatively less popular Ethereum was most discussed upon Facebook but followed by popular blogging and web content websites, Reddit and 4chan.

Within the extensive research data collected as a part of this research, many critical insights were obtained regarding the nature and trends of online discourse preceding and following significant shifts in value for Ethereum and Bitcoin. One of the most important trends extrapolated by the researched data corresponds with the 2-Step Flow of Communication Theory, upon which specific contributors were shown to be the most knowledgeable and influential towards the online discourse held upon these two Cryptocurrencies. Thus, these users mentioned within the research were found repetitively throughout the different inspected dates to be the most involved in the discourse, across the different platforms most popular for use for these discussions. Another trend validated by the research conducted is that which the majority of discourse held regarding these Cryptocurrencies was that the majority of discussions held were done so upon social media platforms, not on financial blogs and websites. This trend is critical as it indicates where the majority of Cryptocurrency investors hold their discussions online, moreover, where they seek their information on the topic.

Viable insight towards the influence of the online discourse upon Cryptocurrency valuation is seen within the trends of the actual discussion held preceding the dramatic shifts in value. For example, users were shown to repetitively use keywords closely related to indication of impending action of commerce regarding the currency such as "Buy/Sell", indicating a plurality of immediate actions of trade by the invested public. Additionally, many results of keywords such as "Virtual assets", indicate a large and rising interest of potential and impending investors which may lead to an augmentation in the value of the coins based on these new investors demonstrating their interest in this cutting-edge 
economy. By highlighting these aforementioned online trends of behavior in the context of discourse held upon Ethereum and Bitcoin, it has become increasingly evident that the online sphere with a strong emphasis upon social media platforms, has exceeded the source of information for individuals using online discourse, rather, this online discourse has arguably become the largest influencer upon the values of these Cryptocurrencies. Thus, specific individuals play a tremendous role as strong influencers upon people's investment behavior along with which platforms appear to be the most influential..

The collected data indicated that the quantity of online discourse held on the topic of Bitcoin was repetitively held on Facebook, Reddit, and 4chan, ranging from approximately $35 \%$ to $15 \%$ respectively. The outlier to these platforms as one of the more popular online venues for this discourse was advfn.com, which serves as an active brokerage website. However, this site also provides a forum for traders to communicate with one another publicly, with the average of approximately $10-15 \%$ of online discourse of Bitcoin held on this platform. The data extrapolated for Ethereum using Buzzilla indicated that the majority of online discourse surrounding the Cryptocurrency was also held upon the major social media platforms such as Facebook, Twitter, and other varying sites. Twitter provided the highest average of online discourse with approximately $15 \%$ across all three inspected date ranges, while Facebook was noted to pertain to approximately $8 \%$ of the online discourse (Buzzilla, 2018).

As in any social media or social platform, one of the most relevant aspects to consider is the activity or frequency of those posting or participating in the content of the platform. As mentioned in the section of the results, one of the most frequent participants of online discourse for both examined Cryptocurrencies, was "Anonymous". However, it should be noted that examining "Anonymous" as an individual user is incorrect as many online readers and posters regarding all content online upon subscription-based websites choose to go by pseudonyms. Thus, it is presumable that there is a proportionally higher number of users who choose to identify as "Anonymous", far more than non-generic names, thus grouping the behavior of many different users under the same title opposed to separating the contribution and participation per each individual user. The disadvantage of strategically overlooking the data attributed to "Anonymous" is large as this pseudonym consistently appears as the highest participant in online discourse during the examined periods. Comparatively, the secondly repetitive most contributing user was identified by their pseudonym "Tyler Durden”, who was specifically more involved in all searches relevant to Ethereum. However, this user's contributions were exponentially smaller than 
the leading "Anonymous" due to the aforementioned grouping of many users under the same title (Buzzilla, 2018). Furthermore, it is imperative to consider the nature of minimal number of repetitive participants to the online discourse according to Jakob Nielsen's 909-1 Participation analysis of users on social media and online platforms. According to this theory, $90 \%$ of all internet users are defined as "lurkers", whereby they absorb the information with no contribution or participation. The following $9 \%$ of all internet users are intermittent contributors, who very seldom add to the web "fauna" and "flora" of content. Finally, the remaining $1 \%$ of internet users are highlighted as the heavy contributors, who are the highest contributors of web content, often most personally vested in the relevant matter (Nielsen, 2006).

Additionally, as Cryptocurrencies can be referred to under several titles such as their full names or their ticker symbols, it is imperative to understand which yielded more participation. One must consider a possible theory that those more frequently participating in the Cryptocurrencies' ticker symbols opposed to their full title are more likely to be economically savvy and involved. However, it cannot be assumed that the more popular title of online discourse had higher influence upon the ultimate value of the relevant currency. However, it is notable to correlate the popularity of discourse according to the relevant platform as higher participation according to the coin's full name was statistically more significant on Facebook, whereas the Ticker symbol was more significant on Twitter. Thus, data indicated that nearly in all of the analyzed time frames, online discourse was significantly higher according to the currencies' full names opposed to their ticker symbols (Buzzilla, 2018). Finally, it is critical to denote that discourse cannot be unequivocally determined as the causality of the shift in Cryptocurrency value, however it may be a strong indicator of influence leading to change in investor behavior resulting in such movement.

However, regarding the integrity of the data, one of the aspects of the data collection that may pose as a hindrance toward the applicability of the results is the language of search. By limiting Buzzilla's search parameters to finding results solely in English, many relevant search results and inquiries which could have potentially further established the assertion or possibly undermined it, were overlooked in order to maintain the consistency of the research through language. The variety of different Cryptocurrencies in existence, specifically those examined in this research are traded throughout a multitude of different nations and discussed online using a wide variety of diverse languages. Thus, it is arguable that additional data which could provide critical insight was overlooked in order to 
maintain consistency of different parameters of the data which were examined. For example, Facebook is one of the most popular social media platforms used in the Western Hemisphere however, the Russian public predominantly uses the local social media platform VKontakte. (McDonald, 2014)

As in all research conducted, there are limitations to the methodology used, partly deriving from the tools used to collect the data and otherwise resulting from the scope of what is being examined along with the parameters set by the researcher. Regarding the research conducted in this piece, one must consider the different aspects that may be considered as hindrances limiting the widespread applicability of the data and subsequent analysis, along with the narrowed scope of data collected in comparison to the abundance of available data in existence concerning this topic. Firstly, in the context of the limitations to the data collected one must regard the notion of the selected date ranges used for reference in order to observe the steep shifts in value and corresponding online discourse. The points of reference selected by the researcher were done so arbitrarily according to what appeared to be the three most dramatic points of change in each currency's value, along with evaluating the preceding and following days in order to procure the data of the discourse immediately preceding and following the dramatic changes. The possible limitation of this methodology could be overlooking additional viable and critical data to the theorized phenomenon by choosing an interval which lacks the necessary timeline including imperative data.

An additional limitation to the research conducted was the data collected regarding the pseudonym of "Anonymous". It is arguably unreliable to attribute any consistency to data collected from this username, despite being one of the major contributors to content preceding and following shifts in both coin values. The reason for this, is that the pseudonym of "Anonymous" is one that can be used by many users and is very common for use in the online arena for individuals avoiding any personal indicators within their usernames. As such this username could theoretically be repetitively used by an abundance of users providing separate data regarding patterns of their online behavior which is then compiled as one, due to the common username. Finally, one of the largest limitations to consider regarding this research is the tool used to collect the data of online discourse and activity, Buzzilla. Despite the many merits which this tool holds towards data collection of online discourse, it is limited to examining data which dates back to two years ago. Resultantly, the researcher was limited and unable to examine critical data which could have provided tremendous insight into aspects of the Cryptocurrencies such as the nature 
of the online discourse when they were founded or significant economic events during this time period.

As global economies are collectively shifting towards virtual currencies, several of which are relying upon the predominance of Cryptocurrencies, many possible future directions for research arise accordingly. One of the most important questions raised by the data yielded in this research has to do with the intended manipulation of online discourse in order to sway the value of Cryptocurrencies either upwards or downwards. Many of the concerns raised regarding the security or stability of Cryptocurrencies have been discussed in the context of cybersecurity however, resultantly people have overlooked the importance of social influence. Furthermore, the concept arises of the perils of widespread manipulation of investors using social influence in order to dramatically augment or lower the value of the different currencies, ultimately affecting the Crypto-economy dramatically. Thus, the rising question for future research would be, would it be possible to augment or reduce the value of Cryptocurrencies by manipulating and influencing the surrounding online discourse? 
The Relationship of Online Discourse on the Values of Bitcoin and Ethereum

\section{Conclusion}

The worlds of Cryptocurrencies and online discourse are both extremely intricate, specifically when examining the implied correlational relationship of influence. Yet, despite their very complex nature it is critical to understand their intertwined effects upon one another. With Bitcoin and Ethereum maintaining presence as the most powerful and collectively valuable currencies in the Cryptocurrency market, it is imperative to fully understand what the different influences upon their values are, as they are not regulated by any formal government or entity. As some may hypothesize regarding a reciprocal relationship where both entities influence each other in turn, this paper addressed the effects of online discourse upon the values of Bitcoin and Ethereum. Thus, it is important to recognize a trend whereby the rise in online discourse precedes a significant change in currency value.

By using a holistic data collection tool such as Buzzilla, the extraction of critical data of the extensive online discourse regarding Ethereum and Bitcoin was thorough. Using this tool was not only important regarding the quantified data collected concerning the overall online discourse surrounding these two Cryptocurrencies, but rather provided indicative information towards the reasoning of perhaps why these events transpired. Data such as site segmentation, user segmentation, keyword prevalence, and others were able to contribute to the variety in researching the assumption of a correlation between both the nature and quantity of online discourse and the fluctuation of Ethereum and Bitcoin.

As seen in the collected data, there is a visible spike in regarding the prevalence of online discourse surrounding the keywords searched surrounding Bitcoin and Ethereum. Furthermore, the same trend was visible when examining the online discourse surrounding a significant drop in these currencies. This data is significant in establishing the possibility of correlational influence between these two entities as it shows a reactionary process resulting from the quantized change in discourse. Furthermore, one must note the most influential participants during the periods of examinations for the respective currencies. By doing so, the data is given added value not only by considering the "how" aspect of the online discourse, but moreover the "who", regarding who are the leading figures in the online discourse influencing the change in currency values.

Overall, unlike many other forms of investment subjected to extrinsic influence, Cryptocurrencies appear to be more autonomous and unscathed by external variables. Thus, it was important to understand if the investors, as those with the direct contact to the 
currencies, potentially have critical influence over the coin values beyond simply buying or selling. Through this research several important assertions arise as critical for the economic viability of this economy. Firstly, one may theorize that through manipulation of online discourse, either by contributing extraordinary amounts or manipulating key participants, one may be able to influence the market by exerting augmented participation directly relevant to specific coins. Furthermore, social scientists can analyze the mindset leading to posts and online discourse ultimately contributing to the change in coin value. This goes beyond the observational nature of trends leading to deductions regarding market behavior, rather, how to incite shifts in the economy by leveraging influence, specifically by employing or manipulating online discourse. 
The Relationship of Online Discourse on the Values of Bitcoin and Ethereum

\section{$\underline{\text { References }}$}

Aral, S., Muchnik, L., \& Sundararajan, A. (2009). Distinguishing influence-based contagion from homophily-driven diffusion in dynamic networks. Proceedings Of The National Academy Of Sciences, 106(51), 21544-21549. doi: 10.1073/pnas.0908800106

Ardis, M., \& Marcolin, B. (2017). Erratum to: Diffusing Software Product and Process Innovations. Diffusing Software Product And Process Innovations, E1-E1. doi: 10.1007/978-0-387-35404-0_19

Bandyk, M., \& Schwartz, A. (2009). The Origins Of The Financial Crisis, According To Anna J. Schwartz. US News. Retrieved 3 April 2018, from https://money.usnews.com/money/blogs/capital-commerce/2009/06/15/the-originsof-the-financial-crisis-according-to-anna-j-schwartz

Beattie, A. (2018). The Birth of Stock Exchanges. Investopedia. Retrieved 23 February 2018, from https://www.investopedia.com/articles/07/stock-exchange-history.asp

Bentov, I., Lee, C., Mizrahi, A., \& Rosenfeld, M. (2014). Proof of Activity. ACM SIGMETRICS Performance Evaluation Review, 42(3), 34-37. doi: $10.1145 / 2695533.2695545$

Buzzilla. (2018). Retrieved 6 June 2018, from https://console.buzzilla.com/

Bryant, J., \& Miron, D. (2004). Theory and Research in Mass Communication. Journal Of Communication, 54(4), 662-704. doi: 10.1111/j.1460-2466.2004.tb02650.x

Cheah, E., \& Fry, J. (2015). Speculative bubbles in Bitcoin markets? An empirical investigation into the fundamental value of Bitcoin. Economics Letters, 130, 32-36. doi: 10.1016/j.econlet.2015.02.029

CoinMarketCap. (2018). All Cryptocurrencies. Retrieved from https://coinmarketcap.com/all/views/all/

Coleman, J., Katz, E., \& Menzel, H. (1957). The Diffusion of an Innovation Among Physicians. Sociometry, 20(4), 253-270.

Draupnir, M. (2016). How are New Bitcoins Created and Generated?. Bitcoinmining.com. Retrieved 28 April 2018, from https://www.bitcoinmining.com/how-are-newbitcoins-created/

ETH \$1K Thread. (2018). Retrieved from http://boards.4chan.org/biz/thread/5753224

Farell, R. (2015). An Analysis of the Cryptocurrency Industry (Wharton Research Scholar). University of Pennsylvania.

FXCM. (2015). The History of Currency - FXCM. FXCM Insights. Retrieved 13 February 2018, from https://www.fxcm.com/insights/the-history-of-currency/ 
The Relationship of Online Discourse on the Values of Bitcoin and Ethereum

Godbole, O., \& Sinclair, S. (2018). Ethereum Price - CoinDesk. Retrieved from https://www.coindesk.com/ethereum-price/

Gorsline, E. (2018). Behind the Scenes of Cryptocurrency Exchanges: Secrets, Strategies, and More. Retrieved from https://coincentral.com/behind-the-scenes-ofCryptocurrency-exchanges/

Gulamhuseinwala, I., Bull, T. and Lewis, S. (2015). FinTech is gaining traction and young, high-income users are the early adopters. The Journal of Financial Perspectives: FinTech, 3(3), p.3.

Han, J., \& Liang, Y. (1995). The Historical Performance of Real Estate Investment Trusts. Journal Of Real Estate Research, 10(3), 235-262.

Hayat, T., Brainin, E., \& Neter, E. (2017). With some help from my network: supplementing eHealth literacy with social ties. Journal of medical Internet research, 19(3).

Hayat, T., Hershkovitz, A., \& Samuel-Azran, T. (2019). The independent reinforcement effect: The role diverse social ties play in the credibility assessment process. Public Understanding of Science, 28(2), 201-217.

Hayat, T., \& Hershkovitz, A. (2018). The role social cues play in mediating the effect of eWOM over purchasing intentions. Journal of Customer Behavior. 17 (3), 173-187.

Hayat, T, Lesser, O., \& Samuel-Azran, T (2017). Gendered discourse patterns on online social networks: a social network analysis perspective. Computers in Human Behavior. 77, 132-139.

Hayes, A. (2017). Cryptocurrency value formation: An empirical study leading to a cost of production model for valuing bitcoin. Telematics And Informatics, 34(7), 13081321. http://dx.doi.org/10.1016/j.tele.2016.05.005

Investopedia. (2018). What are the differences between investing in real estate and stocks? Retrieved 14 February 2018, from https://www.investopedia.com/ask/answers/100214/what-are-differences-betweeninvesting-real-estate-and-stocks.asp

Jiao, Y., \& Ye, P. (2014). Mutual fund herding in response to hedge fund herding and the impacts on stock prices. Journal Of Banking \& Finance, 49, 131-148. doi: 10.1016/j.jbankfin.2014.09.001

Katz, E. (1957). The Two-Step Flow of Communication: An Up-To-Date Report on an Hypothesis. Political Opinion Quarterly, 21 (1), 61-78. http://dx.doi.org/10.1086/266687

Knowledge@Wharton. (2017). How Blockchain Technology Can Serve the Have-nots Knowledge@Wharton. Retrieved 13 February 2018, from http://knowledge.wharton.upenn.edu/article/blockchain-technology-can-serve-nots/ 
The Relationship of Online Discourse on the Values of Bitcoin and Ethereum

Lazersfeld, P., \& Merton, R. (1948). Mass Communication, Popular Taste, and Organized Social Action. The Communication of Ideas, VII, 95-118.

Lee, T. (2014). Five years of Bitcoin in one post. Washington Post. Retrieved 25 April 2018, from https://www.washingtonpost.com/news/the-switch/wp/2014/01/03/fiveyears-of-bitcoin-in-one-post/?noredirect=on\&utm_term=.2e642407a290

Li, X., \& Wang, C. (2017). The technology and economic determinants of Cryptocurrency exchange rates: The case of Bitcoin. Decision Support Systems, 95, 49-60. doi: 10.1016/j.dss.2016.12.001

Lundblad, J. P. (2003). A review and critique of rogers' diffusion of innovation theory as it applies to organizations. Organization Development Journal, 21(4), 50-64. Retrieved from https://search.proquest.com/docview/197971687? accountid=38867

Luther, W. (2015). Cryptocurrencies, Network Effects, and Switching COSTS. Contemporary Economic Policy, 34(3), 553-571. http://dx.doi.org/10.1111/coep.12151

Mai, F., Bai, Q., Shan, Z., Wang, X., \& Chiang, R. (2015). From bitcoin to big coin: The impacts of social media on bitcoin performance. SSRN Electronic Journal.

Martucci, B. (2018). What Is Cryptocurrency - How It Works, History \& Bitcoin Alternatives. Moneycrashers.com. Retrieved 13 February 2018, from https://www.moneycrashers.com/Cryptocurrency-history-bitcoin-alternatives/

Marx, L., \& Smith, M. (1994). Does Technology Drive History?. Cambridge, MA: MIT Press.

McCombs, M., Shaw, D., \& Weaver, D. (2013). Communication and Democracy. Hoboken: Taylor and Francis.

McDonald, M. (2014). Social Network Matchup: Vkontakte vs Facebook in Russia Russian Search Marketing. Retrieved from https://russiansearchmarketing.com/social-network-matchup-vkontakte-vrsfacebook-russia/

Nielsen, J. (2006). Participation Inequality: The 90-9-1 Rule for Social Features. Retrieved from https://www.nngroup.com/articles/participation-inequality/

Nisbet, M., \& Kotcher, J. (2009). A Two-Step Flow of Influence?. Science Communication, 30(3), 328-354. doi: 10.1177/1075547008328797

Noonan, K. (2018). Why I Won't Buy Ethereum. Retrieved from https://www.fool.com/investing/2018/04/02/why-i-wont-buy-ethereum.aspx

Official CryptoTalk Thread. (2018). Retrieved from https://www.tigerdroppings.com/rant/money/official-cryptotalkthread/69916592/page-231/

Park, R. (1923). The Natural History of the Newspaper. American Journal Of 
The Relationship of Online Discourse on the Values of Bitcoin and Ethereum

Sociology, 29(3), 273-289. doi: 10.1086/213596

Phillips, R., \& Gorse, D. (2017). Predicting Cryptocurrency price bubbles using social media data and epidemic modelling. 2017 IEEE Symposium Series On Computational Intelligence (SSCI). doi: 10.1109/ssci.2017.8280809

Pick, L. (2015). Russian Finance Minister: Bitcoin Ban to Take Effect This Year |Finance Magnates. Retrieved from https://www.financemagnates.com/Cryptocurrency/news/russian-finance-ministerbitcoin-ban-to-take-effect-this-year/

Rosic, A. (2017). What is Cryptocurrency: Everything You Need To Know [Ultimate Guide]. Blockgeeks. Retrieved 28 April 2018, from https://blockgeeks.com/guides/what-is-Cryptocurrency/

Salami, I. (2017). Terrorism Financing with Virtual Currencies: Can Regulatory Technology Solutions Combat This?. Studies In Conflict \& Terrorism, 1-22. http://dx.doi.org/10.1080/1057610x.2017.1365464

Shaw, W. (1896). The history of currency, 1252-1894. New York: Putnam.

Shiller, R. (1987). Investor Behavior in the October 1987 Stock Market Crash: Survey Evidence. Monetary Economics, (2446). http://dx.doi.org/10.3386/w2446

Sundararajan, S. (2018). Bitcoin Price Index - Real-time Bitcoin Price Charts. Retrieved from https://www.coindesk.com/price/

Tarasiewicz, M., \& Newman, A. (2015). Cryptocurrencies as Distributed Community Experiments. Handbook Of Digital Currency, 201-222. doi: 10.1016/b978-0-12802117-0.00010-2

Tassev, L. (2018). Court Strikes Down Ban on 40 Bitcoin Sites in Russia - Bitcoin News. Retrieved from https://news.bitcoin.com/court-strikes-ban-40-bitcoin-sites-russia/

Tillier, M. (2018). What Is A Cryptocurrency?. NASDAQ.com. Retrieved 13 February 2018, from https://www.nasdaq.com/article/what-is-a-Cryptocurrency-cm910816

Turner, J. (1993). Social influence. Milton Keynes: Open University Press.

University of Twente. (2015). Two Step Flow Theory. Retrieved 19 December 2015, from https://www.utwente.nl/cw/theorieenoverzicht/Theory\%20Clusters/Mass\%20Medi a/Two_Step_Flow_Theory-1/

Xie, P. (2017). Predicting Digital Currency Market With Social Data: Implications of Network Structure and Incentive Hierarchy (PhD). Georgia Institute of Technology.

Zuckerman, M. (2018). 80\% Of All Bitcoins Already Mined, Only 4.2 Million Coins Left Until Supply Cap. Retrieved from https://cointelegraph.com/news/80-of-allbitcoins-already-mined-only-42-million-coins-left-until-supply-cap 